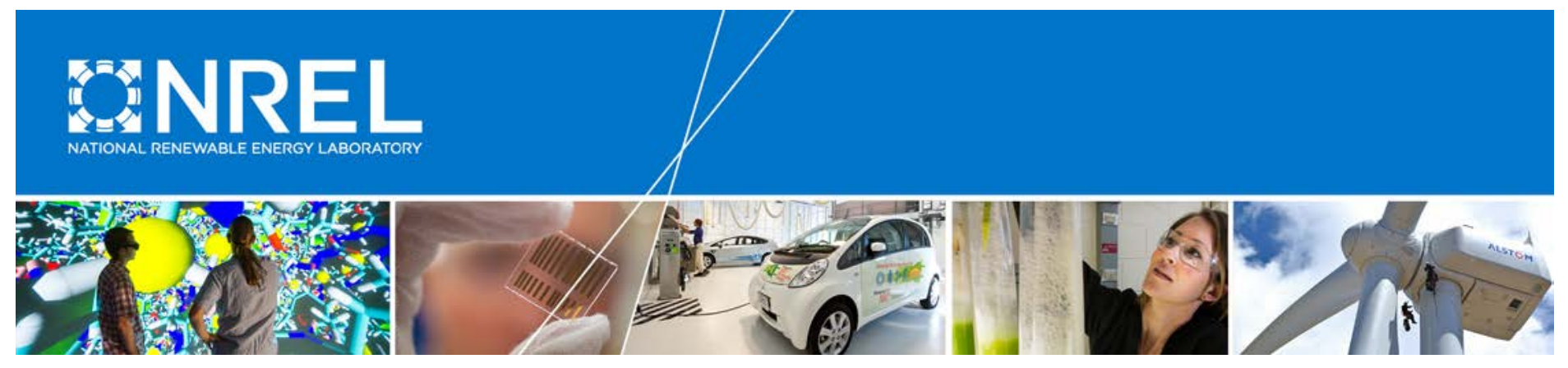

\title{
An Initial Evaluation of Siting Considerations on Current and Future Wind Deployment
}

Suzanne Tegen, Eric Lantz, Trieu Mai, Donna Heimiller, and Maureen Hand National Renewable Energy Laboratory

Eduardo Ibanez GE Energy Consulting

NREL is a national laboratory of the U.S. Department of Energy Office of Energy Efficiency \& Renewable Energy Operated by the Alliance for Sustainable Energy, LLC

This report is available at no cost from the National Renewable Energy Laboratory (NREL) at www.nrel.gov/publications.

Technical Report

NREL/TP-5000-61750

July 2016

Contract No. DE-AC36-08G028308 


\section{An Initial Evaluation of Siting Considerations on Current and Future Wind Deployment}

Suzanne Tegen, Eric Lantz, Trieu Mai, Donna Heimiller, and Maureen Hand National Renewable Energy Laboratory

Eduardo Ibanez GE Energy Consulting

Prepared under Task No. WE14.CF03
NREL is a national laboratory of the U.S. Department of Energy Office of Energy Efficiency \& Renewable Energy Operated by the Alliance for Sustainable Energy, LLC

This report is available at no cost from the National Renewable Energy Laboratory (NREL) at www.nrel.gov/publications.

\section{Technical Report}

NREL/TP-5000-61750

July 2016

Contract No. DE-AC36-08G028308
National Renewable Energy Laboratory 15013 Denver West Parkway

Golden, CO 80401

303-275-3000 • www.nrel.gov 


\section{NOTICE}

This report was prepared as an account of work sponsored by an agency of the United States government. Neither the United States government nor any agency thereof, nor any of their employees, makes any warranty, express or implied, or assumes any legal liability or responsibility for the accuracy, completeness, or usefulness of any information, apparatus, product, or process disclosed, or represents that its use would not infringe privately owned rights. Reference herein to any specific commercial product, process, or service by trade name, trademark, manufacturer, or otherwise does not necessarily constitute or imply its endorsement, recommendation, or favoring by the United States government or any agency thereof. The views and opinions of authors expressed herein do not necessarily state or reflect those of the United States government or any agency thereof.

This report is available at no cost from the National Renewable Energy Laboratory (NREL) at www.nrel.gov/publications.

Available electronically at SciTech Connect http:/www.osti.gov/scitech

Available for a processing fee to U.S. Department of Energy and its contractors, in paper, from:

U.S. Department of Energy

Office of Scientific and Technical Information

P.O. Box 62

Oak Ridge, TN 37831-0062

OSTI http://www.osti.gov

Phone: 865.576.8401

Fax: 865.576.5728

Email: reports@osti.gov

Available for sale to the public, in paper, from:

U.S. Department of Commerce

National Technical Information Service

5301 Shawnee Road

Alexandria, VA 22312

NTIS http://www.ntis.gov

Phone: 800.553 .6847 or 703.605 .6000

Fax: 703.605.6900

Email: orders@ntis.gov 


\section{Acknowledgments}

The authors would like to thank Jose Zayas, Patrick Gilman, and Mark Higgins of the U.S. Department of Energy (DOE) Wind and Water Power Technologies Office for funding this work. In addition, for expert input on radar, we thank Ben Karlson, Dave Minster, and Bruce LeBlanc of Sandia National Laboratories and Mike Aimone of the Department of Defense Clearinghouse. For expert input on wildlife, we thank Cris Hein of Bat Conservation International, Taber Allison and Abby Arnold of the American Wind Wildlife Institute, and Heidi Souder of the University of Colorado Boulder. For strategic guidance, we thank Rich Tusing (contractor) with DOE as well as Ian Baring-Gould and Mark Jacobson of the National Renewable Energy Laboratory (NREL). For contributions to specific portions of this work, we thank Kathy Belyeu, KC Hallett, and Andrew Perry, all formerly of NREL, as well as Venkat Krishnan, Jessica Lin-Powers, Anthony Lopez, Karin Sinclair, and Bob Thresher of NREL. We also extend thanks to our many wind industry contacts who provided data, candid discussions, other critical insights, and review throughout the development and completion of this project. Finally, for their careful review of prior manuscripts, we thank Scott Gossett, Mike Meshek, Kathy O'Dell, Dave Corbus, and Brian Smith of NREL. 


\section{List of Acronyms}

$\begin{array}{ll}\text { BA } & \text { balancing area } \\ \text { BAU } & \text { business-as-usual } \\ \text { DoD } & \text { U.S. Department of Defense } \\ \text { DOE } & \text { U.S. Department of Energy } \\ \text { FAA } & \text { Federal Aviation Administration } \\ \text { GIS } & \text { geographic information system } \\ \text { GW } & \text { gigawatt } \\ \text { km } & \text { kilometer } \\ \text { kW } & \text { kilowatt } \\ \text { kWh } & \text { kilowatt-hour } \\ \text { LCOE } & \text { levelized cost of energy } \\ \text { MW } & \text { megawatt } \\ \text { MWh } & \text { megawatt-hour } \\ \text { NCF } & \text { net capacity factor } \\ \text { NPV } & \text { net present value } \\ \text { NREL } & \text { National Renewable Energy Laboratory } \\ \text { PPA } & \text { power purchase agreement } \\ \text { ReEDS } & \text { Regional Energy Deployment System } \\ \text { TRG } & \text { techno-resource group } \\ \text { TWh } & \text { terawatt-hour }\end{array}$




\section{Executive Summary}

The United States had more than 74 gigawatts (GW) of operating wind power capacity consisting of more than 52,000 wind turbines as of year-end 2015. The U.S. Department of Energy's (DOE's) Wind Vision: A New Era for Wind Power in the United States suggests scenarios where installed wind capacity could grow to more than $400 \mathrm{GW}$ by 2050 , which represents enough capacity to serve $35 \%$ of the nation's electricity demand. Although the cost of wind technology is generally declining and expected to continue to decline, wind power projects and future deployment levels are also affected by siting considerations. Potential impacts include increased development costs and a shift to lower-quality resource areas, both of which could increase the cost of wind energy and reduce long-term wind power deployment.

This analysis seeks to provide data and insights that can be used by stakeholders to understand and potentially mitigate impacts of some siting considerations on U.S. wind power deployment. More specifically, we examine the wind power project development process to understand how certain siting considerations are typically addressed and to estimate the impact of these siting considerations on project development costs and wind resource potential. We use capacity expansion modeling to understand how future wind power deployment might be affected by siting considerations. This latter portion of the work expands on long-term deployment scenarios originally explored in DOE's

Wind Vision.

Three specific types of siting considerations are explored:

- Wildlife - avian and bat species that live in, near, or migrate through potential wind development areas

- Radar - the potential for wind turbines to interfere with radar signals

- Public engagement — concerns or considerations that stakeholders or communities near existing or proposed wind power projects may raise.

Consistent with the observed anecdotal evidence, we find siting considerations often result in upward pressure on development costs and extended development timelines. In some cases, operating costs are also increased. Notwithstanding this upward pressure and the project-level risks associated with specific siting considerations, development costs remain a relatively small portion of all-in project capital costs.

Focusing on the three siting considerations identified above and under the most restrictive siting conditions considered, geographic information system (GIS) analysis indicates that $80 \%$ of the potential land-based wind resource capacity considered developable today could be affected by at least one of the siting considerations. This finding suggests that managing siting considerations is an essential part of the wind power business for much of the country. At the same time, the immensity of the U.S. wind resource still leaves more than 1,000 GW of wind potential that may be unaffected by the siting considerations examined. 
Long-term capacity expansion modeling results generally suggest that wind is an increasingly cost-effective and competitive energy resource. By 2050, business-as-usual (BAU) scenarios support levels of wind deployment more than three times current levels with widespread geographic distribution of installed capacity. However, applying these siting restrictions results in reductions in 2030 and 2050 wind capacity of up to $14 \%$ and $28 \%$, respectively, relative to BAU. Coupling siting considerations with limits on post2020 transmission expansion could result in a total reduction in 2050 economic wind deployment by up to $40 \%$.

Siting considerations did not preclude the realization of the Wind Vision Study Scenario in part due to the vast U.S. wind potential. However, scenarios that reflected siting considerations and transmission restrictions did result in some shifts of deployed wind capacity, due to reliance on lower-quality sites and increased curtailment. In addition, the represented siting considerations and transmission restrictions affected cost metrics reported in Wind Vision. More specifically, cumulative electric-sector expenditures for the Study Scenario could increase by up to $4 \%$ on a net-present-value basis, under the most stringent siting scenarios considered.

While the model results provide insights from the U.S. electric system perspective, siting considerations are ultimately local, and model findings need to be supplemented by analysis of the project development process and potential mitigating strategies. In addition, as more wind is deployed and the cost of generating wind power decreases, project developers may need to do more to address the siting considerations named above as proximity to radar and human and wildlife populations increases. Evaluation of these siting considerations at early stages in project development is vital for developers and other stakeholders. Thus, mechanisms to identify the impacts of wind energy on wildlife and human uses, develop mitigation strategies, and encourage long-term land use and airspace planning could help minimize potential disruption of appropriate wind deployment on private and public land.

Future analysis would benefit from more formal and larger survey efforts to better ascertain the representativeness of experiences and data captured in this effort. In addition, higher-resolution data for geographic and cost impacts and more sophisticated siting consideration layers could enhance the representations of the siting considerations applied here and further inform the potential impacts of siting on wind deployment. 


\section{Table of Contents}

Executive Summary

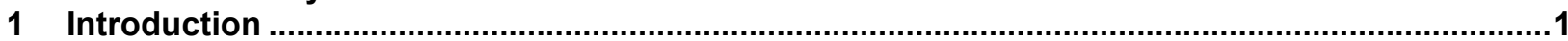

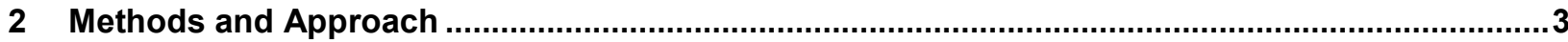

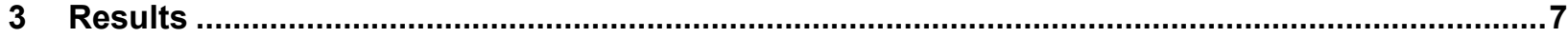

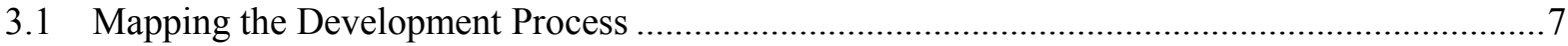

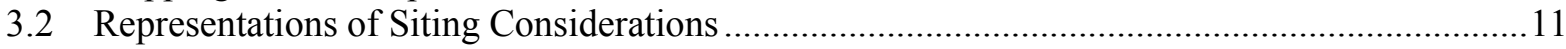

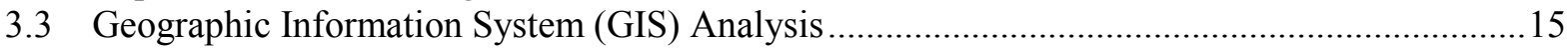

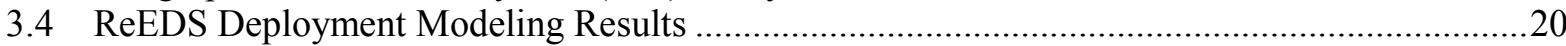

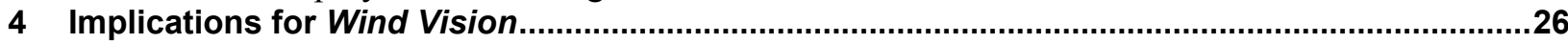

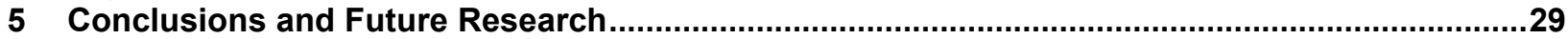

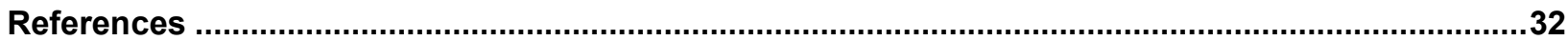

Appendix A. Detailed Project Development Flowcharts …..........................................................33

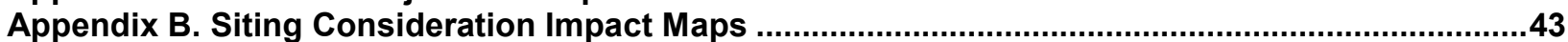

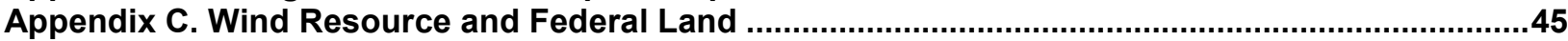




\section{List of Figures}

Figure 1. Flowchart of wind energy decision and development.....................................................8

Figure 2. Developable land-based wind resource in the United States, quality by technoresource group (left) and quantify (right), based on standard exclusions ................................15

Figure 3. Map of the United States showing an aggregation of the moderate siting consideration representations

Figure 4. Map of the United States showing an aggregation of the high siting consideration representations ....

Figure 5. Histogram of impact on available capacity by TRG (first $1,000 \mathrm{GW}$ in each TRG)............19

Figure 6. Incremental cost for the first $1,000 \mathrm{GW}$ of developable wind potential, based on the combined moderate and high siting consideration representations ....................................20

Figure 7. Land-based wind capacity deployment projections for the BAU scenarios ......................21

Figure 8. Land-based wind capacity deployment by TRG for the BAU scenarios by 2050 ...............21

Figure 9. Land-based wind capacity deployment projections for the Wind Vision

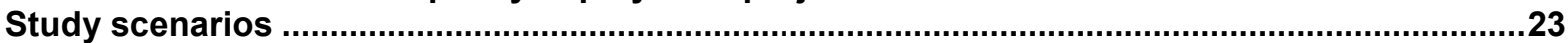

Figure 10. Average electricity price projections for Wind Vision Study scenarios...........................25

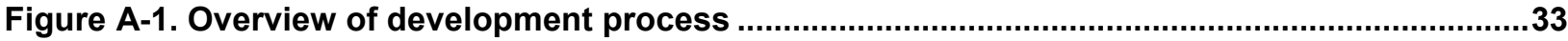

Figure A-2. Stage I of the development process: prospecting …................................................

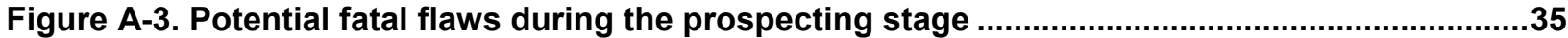

Figure A-4. Potential uncertainties during the prospecting stage .............................................36

Figure A-5. Stage II of the development process: early development ..............................................37

Figure A-6. Potential fatal flaws during early development ..........................................................38

Figure A-7. Stage III of the development process: intermediate development ....................................39

Figure A-8. Potential fatal flaws during intermediate development ...................................................40

Figure A-9. Stage IV of the development process: advanced development .....................................41

Figure A-10. Potential fatal flaws during advanced development....................................................42

Figure B-1. Map of the United States wind resource quality (left) and quantity (right) with

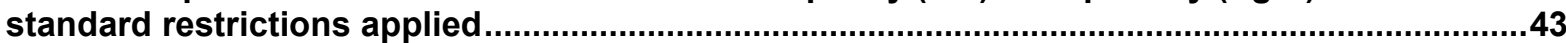

Figure B-2. U.S. wind resource quality with the moderate public engagement representation

Figure B-3. U.S. wind resource quality with the higher public engagement representation............43

Figure B-4. Moderate and highly restrictive radar representations ...................................................44

Figure B-5. Avian and bat species identified for wind wildlife interaction and considered in this work

Figure C-1. U.S. wind resource at $80 \mathrm{~m}$ overlaid with federal lands ..............................................45 


\section{List of Tables}

Table 1. ReEDS Scenario Matrix

Table 2. Phases of Wind Project Development, Critical Tasks, and Estimated Investment Level (2013\$) .10

Table 3. Direct Cost Ranges Associated with Siting Considerations for a Typical 100-MW Wind Project (2013\$)

Table 4. Summary of Cost Adder and Land Restrictions for Each Representation (2013\$).............14

Table 5. Impact of Siting Considerations on Developable Area (Capacity) of Wind Vision by TRG.

Table 6. Change in Retail Electricity Rates and Cumulative (NPV) of Electric-Sector Expenditures, Relative to the Wind Vision Baseline Scenario ${ }^{a}$

Table C-1. Impact of Federal Lands on Developable Area (Capacity) of Wind Vision by TRG . 


\section{Introduction}

The United States had more than 74 gigawatts $(\mathrm{GW})$ of operating wind power capacity comprising more than 52,000 wind turbines as of year-end 2015. ${ }^{1}$ The U.S. Department of Energy's (DOE's) Wind Vision: A New Era for Wind Power in the United States (DOE 2015) suggests plausible scenarios where installed wind capacity could grow to more than $400 \mathrm{GW}$ by 2050 , which represents enough capacity to produce $35 \%$ of the nation's electricity demand. Achieving such high penetrations of wind power could require more wind turbines be installed in or near communities across the country. Future growth of this magnitude could also bring to the forefront siting challenges, including radar, wildlife, other environmental concerns, and community concerns. Anecdotal evidence from industry interviews and media coverage already suggests that addressing the concerns of multiple stakeholders - including regulatory bodies like the Federal Aviation Administration (FAA), U.S. Fish and Wildlife Service, and U.S. Environmental Protection Agency and community stakeholders such as county commissioners and local planning and zoning boards - is becoming increasingly labor and resource intensive. Even with these recent and potential future trends, we know that wind power can and does coexist with sensitive wildlife and human land and airspace uses.

This report represents an initial effort to qualitatively and quantitatively enhance understanding of the impacts that siting considerations are having and could potentially have on wind energy development and deployment. First, we explored three of the siting issues wind energy developers need to consider in their process: public engagement (also known as public acceptance), radar, and wildlife. For this part of the study, we addressed three primary research questions:

1. What is the process for wind development in the United States? At which stages do specific siting considerations enter the decision-making process, and when might they cause project delays or cancellation?

2. What are the direct and indirect costs of specific siting considerations to wind deployment for a typical project?

3. How do specific siting considerations affect the amount of land available for potential wind development in the United States?

After gaining an understanding of the development process, we created GIS-based data layers for each of the three selected siting considerations and overlaid them with the U.S. wind resource to determine where they overlapped with each other and with the wind resource. We used these overlapping land areas as an indicator of the extent to which these siting considerations may reduce the amount of developable land.

In the final part of the study, we used the National Renewable Energy Laboratory's (NREL's) Regional Energy Deployment System (ReEDS) model to analyze the effect of the same three siting considerations on the future wind power deployment scenarios

\footnotetext{
${ }^{1}$ DOE statistics available at: http://energy.gov/eere/wind/windexchange.
} 
originally analyzed in DOE's Wind Vision. ${ }^{2}$ In this portion of the work, we considered the following questions:

1. How do these siting considerations impact wind deployment between today and 2050 ?

2. How might these siting considerations impact the cost of achieving future high wind scenarios, including those with $35 \%$ wind energy by 2050 ?

3. What happens if the ability to build long-distance transmission is more constrained in the future?

Although the cost of wind technology is generally declining and expected to continue to decline (Wiser et al. 2015; DOE 2015), these trends could be offset by the potential for increased costs associated with project development as well as a shift toward less-optimal plant sites in order to reduce or avoid siting risks. This analysis seeks to provide data and insights that can be used by stakeholders to understand, and potentially mitigate impacts of, some siting considerations on U.S. wind energy deployment.

\footnotetext{
${ }^{2}$ Description of the ReEDS model is provided in Short et al. (2011) and Wind Vision.
} 


\section{Methods and Approach}

To characterize recent market realities, we conducted semi-structured interviews with wind power project developers and related companies and consultancies. ${ }^{3} \mathrm{We}$ collected qualitative and quantitative data on the development process and the costs - in money, time, or risk - associated with issues outside traditional market or technology considerations. We noted the companies' experience with how these costs may have changed over time or how they may have varied regionally. Companies were asked for cost information for what they considered a typical project and a higher-cost project. In addition, we queried subject matter experts both within and outside the wind power industry (e.g., environmental, wildlife, and engineering consultancies) to ascertain the potential effects of specific siting concerns on a given region or designated habitat area.

We then distilled the information collected into direct costs dedicated to addressing siting challenges (e.g., amount of money spent on media and town board meetings to allay public doubts about wind farms), total capital invested per development phase, time spent per development phase, average project success rate by phase, and percent of land affected by a given species or siting consideration. Using these data, we identified two metrics to further characterize the potential impacts of siting considerations:

1. Cost adder ( $\$$ /kilowatt $[\mathrm{kW}]$ ) - an incremental cost associated with activities needed to address concerns such as how much a developer spent on avian studies before the project was permitted

2. Land area impact (\%) - total or partial land-use constraints on development.

We used these metrics to characterize the impact of specific siting considerations on the available wind resource supply using GIS datasets. As an example, if Indiana bats were present in an area, for the purposes of this study, we did not exclude their entire habitat from development but instead restricted development on $60 \%-80 \%$ of that land. For land areas where other potential siting considerations may be resolved with a specific mitigation measure, an incremental development cost $(\$ / \mathrm{kW})$ was assessed. Depending on the specific issue at hand, a given siting consideration representation may include a cost adder, land-area impact, or both. Mapped representations in Section 3.3 and Appendix B may represent instances where land is severely constrained to development (i.e., a high percentage land-use constraint is placed on development), where developers voluntarily abandon certain areas because they perceive too many development constraints, or areas where there may actually be few or no limits on development even though a specific siting consideration may be present.

Having gathered data on the recent market realities and characterized potential impacts on wind resource supply with GIS analysis, we used NREL's ReEDS model to explore the impacts of siting considerations on future electric-sector deployment scenarios. More specifically, we explored impacts on total system cost, total wind project deployment, and changes in the geographic distribution of deployment. Generally speaking, the

${ }^{3}$ These interviews were conducted in 2012. 
ReEDS scenarios analysis is an expansion of DOE's Wind Vision (DOE 2015) in that it uses the same ReEDS model version and data assumptions and it starts from the same scenarios (e.g., Business-as-Usual [BAU] and the Study Scenario). However, in this analysis, we consider additional scenarios that apply the siting considerations characterizations or representations developed in the initial part of the work effort and noted above.

More specifically, ReEDS modeling relies on resource supply curves that are calculated taking technology, resource, transmission interconnection, land exclusions, and other factors into consideration to develop a location-specific cost for each potential project site within the country. For Wind Vision (DOE 2015) and other published studies using ReEDS, siting difficulty beyond the NREL standard exclusions (Lopez et al. 2012) has not been considered when developing the wind energy supply curve. In contrast, for this project, we developed a new set of supply curves taking into account the potential cost adder and land area effects associated with the additional siting considerations above, and we applied them in scenarios consistent with Wind Vision. Because this analysis focuses on the land-based contributions to forecast wind penetration levels, offshore wind capacity and generation were fixed for all ReEDS scenarios to isolate the effects of landbased siting considerations. ${ }^{4}$

As siting considerations may alter the geographic distribution of deployable wind potential, they might also impact transmission requirements for wind power. To account for potential uncertainty in the ability to deploy transmission, we also modeled two different transmission-related futures. In one, we assumed transmission could expand without restrictions, as was economically justified. In the other, we excluded development of new high-voltage transmission lines after $2020 .^{5}$

In total, we performed 12 model runs with the NREL ReEDS model (Short et al. 2011; DOE 2015). Table 1 summarizes the model runs in this analysis. These model scenarios are organized into two "families." The first family of scenarios reflects BAU conditions. Under BAU conditions, the modeled scenarios assume economic competition between all generation technologies in the power system and policy conditions consistent with legislation as it exists at a given point in time. In this particular analysis, relevant policies (e.g., state renewable portfolio standards) considered are limited to those in effect prior to January $1,2014 .{ }^{6}$ With the BAU scenarios, we evaluate changes in total economic wind deployment as well as changes in the geographic distribution of deployed wind as a function of different siting considerations.

\footnotetext{
${ }^{4}$ Offshore wind penetration levels are fixed by location based on the Wind Vision Central Study Scenario.

${ }^{5}$ ReEDS endogenously includes under-construction transmission projects for model years prior to 2020 .

${ }^{6}$ The analysis does not include the impacts of the U.S. Environmental Protection Agency Clean Power Plan. In addition, the wind production tax credit is assumed expired by the end of 2014. However, we include identified "under construction" projects in 2015 and 2016 that were anticipated to qualify for the production tax credit, and we assume they will be in operation in the 2016 "solve" year. Renewable energy tax credit extensions that were passed in late December 2015 are not considered in the scenario analysis.
} 
The second family of scenarios is based on the Wind Vision Study Scenario. In these scenarios, wind penetration levels for all modeled years are fixed (or prescribed); for example, $10 \%$ of electricity demand is met by wind energy in $2020,20 \%$ in 2030 , and $35 \%$ in $2050 .{ }^{7}$ Accordingly, the energy generated by wind is predetermined; all other electricity resources compete within the economic framework of the model. These scenarios allow us to assess how the relative costs and distribution of deployed wind are affected by siting considerations at relatively higher wind power deployment levels, as compared to BAU.

For each of these two scenario families (Table 1), we explored the effect of siting considerations by utilizing three specific wind resource supply curves:

1. Standard - NREL standard exclusions only

2. Moderate - Combination of all siting consideration representations, including radar, wildlife, and public engagement at moderate levels

3. High - Combination of all siting consideration representations at high levels.

Scenarios are also differentiated by their handling of transmission development, as noted above. Those scenarios that exclude new interregional transmission lines after 2020 are intended to capture the relative value new high-voltage transmission could provide for future wind deployment with different levels of siting challenges. ${ }^{8}$ In addition, they provide a mechanism to reflect potential preferences for local or in-state electricity generation sources. Of course, the exclusion of new interregional transmission lines after 2020 is not intended to represent an expectation or prediction. Were these scenarios to become a reality they would represent a break from recent historical trends. Instead, these scenarios are intended as a simple bounding framework for the purposes of understanding impacts. Actual levels of future interregional transmission siting, development, and commissioning are uncertain but some development is expected to occur.

Table 1 summarizes the 12 scenarios we modeled, from the two scenario families (BAU and Study scenarios), three siting consideration representations, and two different transmission representations. Of these 12 scenarios, two are directly from Wind Vision (DOE 2015): "BAU-Standard" and "Study-Standard."9

\footnotetext{
7 These percentages apply to the combination of land-based and offshore wind. Because only land-based wind was considered for this analysis, we fixed the offshore wind installations to be the same within each family of scenarios. For the Study Scenario, offshore wind comprised 2\% of demand in 2030 and $7 \%$ in 2050 .

${ }^{8}$ Obstacles in expanding transmission infrastructure overlap with many of the siting considerations explored in this report. For this reason, under a future where land access for wind development is restricted, we might expect similar challenges for transmission expansion.

${ }^{9}$ Both of these correspond to the "central" BAU and Study Scenarios from Wind Vision (DOE 2015).
} 
Table 1. ReEDS Scenario Matrix

\begin{tabular}{|c|c|c|c|}
\hline \multirow{2}{*}{$\begin{array}{l}\text { Scenario } \\
\text { "Family" }\end{array}$} & \multirow{2}{*}{$\begin{array}{c}\text { Siting } \\
\text { Consideration } \\
\text { Representation }\end{array}$} & \multicolumn{2}{|c|}{ Transmission } \\
\hline & & $\begin{array}{l}\text { Transmission } \\
\text { not restricted }\end{array}$ & $\begin{array}{l}\text { No new transmission line } \\
\text { built beyond } 2020\end{array}$ \\
\hline \multirow{3}{*}{$\begin{array}{l}\text { Business As } \\
\text { Usual (BAU) }\end{array}$} & Standard & BAU-Standard & BAU-Standard (No Trans) \\
\hline & Combined moderate & BAU-Moderate & BAU-Moderate (No Trans) \\
\hline & Combined high & BAU-High & BAU-High (No Trans) \\
\hline \multirow{3}{*}{$\begin{array}{l}\text { Study } \\
\text { Scenario }\end{array}$} & Standard & Study-Standard & Study-Standard (No Trans) \\
\hline & Combined moderate & Study-Moderate & Study-Moderate (No Trans) \\
\hline & Combined high & Study-High & Study-High (No Trans) \\
\hline
\end{tabular}

The highlighted text represents the levels of the different siting considerations and cases; the names that are not highlighted are the ReEDS scenario names.

For all scenarios presented here, we used the central technology and fuel cost assumptions from Wind Vision. Supplemental details on the technology and fuel cost assumptions are provided in Appendix H and Appendix G of Wind Vision (DOE 2015). Except where noted, all dollar values presented in this report reflect 2013 U.S. dollars. 


\section{Results}

\subsection{Mapping the Development Process}

The developers we worked with provided key input regarding the essential parts of the development process, including input about the typical project development timeline, direct cost estimates, indirect cost estimates, and project development risks. The development process for new utility-scale wind projects is often broken into four stages that precede construction and operations (defined in Figure 1):

- Prospecting

- Early development

- Intermediate development

- Advanced development.

Budgets and resource allocation grow from one stage to the next. At the same time, fatal flaws or unresolvable issues identified at any stage in the process can force the developer to abandon a project or suspend it for future consideration. The first outcome of the interview process was a series of development flowcharts (Figure 1) that defined important development stages and the tasks associated with each stage of a wind project. Appendix A contains detailed flowcharts for each development stage. From the interviews, we found that a typical project development timeline is 5 years: at least 1 year to collect wind resource data at the site and 4 years to obtain grid interconnection approvals, complete the project, and bring it online. Projects are sometimes completed in as few as 3 years but also may take 10 years from "desktop review" to power generation. Interviewees reported that the earlier a fatal flaw can be discovered, the better, in terms of cost. 


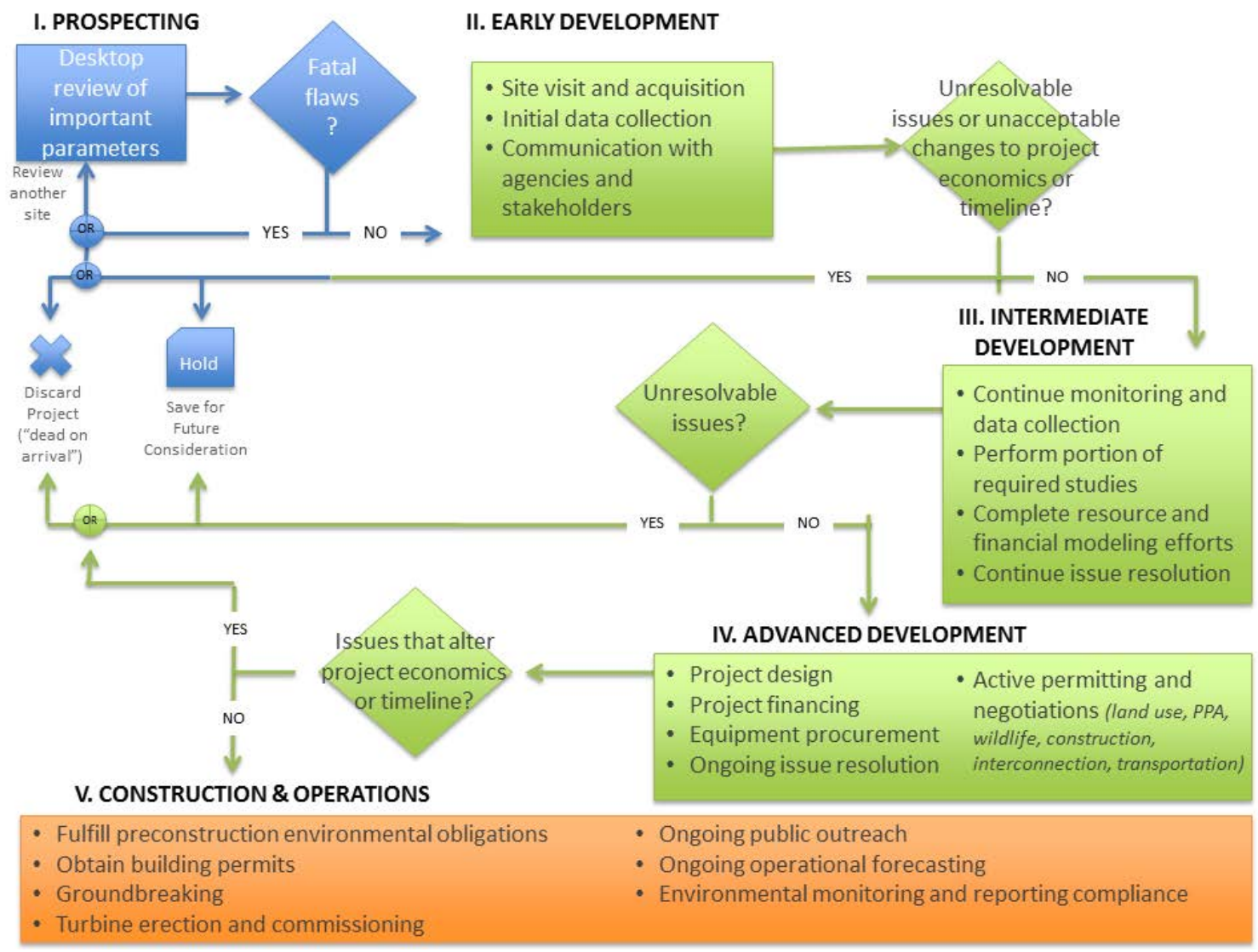

Figure 1. Flowchart of wind energy decision and development

Several additional points of interest emerged from developer interviews:

1. Market conditions have changed significantly across an array of facets in the past decade, including increased flow of capital to non-U.S. development opportunities.

2. Projects are following power purchase agreement (PPA) customers, regardless of siting considerations or optimal wind locations.

3. Developers are starting to conduct site screenings earlier in the process. This quickly screens out sites where there may be fatal flaws, thereby improving the overall success rate.

4. There is some regional variability within the United States on costs of different aspects of project development, such as state and local permitting or conducting wildlife-related studies.

5. Successful project development is about managing uncertainty, project timing, and project costs. Developers expressed a desire for reduced timelines and clearer permitting criteria, even if overall project development costs remain constant.

6. Project development processes are relatively consistent across firms, though their specific market strategies may differ. 


\subsubsection{Direct and Indirect Costs}

The full costs of siting include not only the direct costs required to address potential impacts on wildlife and human uses (such as costs associated with sound, visual impacts, habitat disturbance, and wind-turbine-radar interference) but also the less explicit or secondary costs of failed projects and the risk of future requirements. While the direct costs may be a small portion of the overall project cost, the added sunk costs of projects that never materialize could, with frequent failures, decrease investor interest and ultimately result in lower future deployments, as a function of higher pre-construction development risk.

Qualitative and quantitative data on project development cost, time, and risk were collected from private companies involved in wind power project development. The scope of research was focused on the project development period, after the developer has identified a market of interest and before the beginning of construction. ${ }^{10} \mathrm{We}$ collected information on time and costs associated with various development steps for successful projects and indirect development costs of cancelled or delayed projects. We also collected information on the potential drivers for additional time, cost, or risk at each stage. We asked developers to provide costs for a typical 100-megawatt (MW) project developed between 2008 and 2011, with an average wind speed of 7.25 meters per second $(\mathrm{m} / \mathrm{s})$.

Table 2 summarizes the cost data by project development stage and highlights critical tasks for each stage of development, collected from the firms interviewed. Table 3 details cost estimates by siting consideration and shows potential cost ranges between standard and high-cost projects.

\footnotetext{
${ }^{10}$ The majority of the quantitative data were collected from four firms with an ability (in aggregate) to generate a representative sample of U.S. project development activity. The four firms collectively had experience with more than $6 \mathrm{GW}$ of wind power projects in various U.S. regions. Datasets obtained from these four primary firms were augmented by data from additional project developers who, although they are significant players in the U.S. wind industry, participated in our data collection efforts in a more limited capacity.
} 
Table 2. Phases of Wind Project Development, Critical Tasks, and Estimated Investment Level (2013\$)

\begin{tabular}{|c|c|c|}
\hline Development Stage & Critical Tasks & $\begin{array}{l}\text { Investment } \\
\text { Level per kW }\end{array}$ \\
\hline Phase I - Prospecting & $\begin{array}{l}\text { Assess market strength } \\
\text { Desktop review of important parameters: Evaluate } \\
\text { preliminary project economics } \\
\text { Assess permitting needs }\end{array}$ & $\$ 0.25-\$ 0.50$ \\
\hline $\begin{array}{l}\text { Phase II - Early } \\
\text { development }\end{array}$ & $\begin{array}{l}\text { Site visit and acquisition } \\
\text { Initial data collection } \\
\text { Communication with agencies and stakeholders }\end{array}$ & $\$ 5-\$ 7$ \\
\hline $\begin{array}{l}\text { Phase III - Intermediate } \\
\text { development }\end{array}$ & $\begin{array}{l}\text { Continued monitoring and data collection } \\
\text { Resource and financial modeling } \\
\text { Perform a portion of siting studies } \\
\text { Ongoing issue resolution }\end{array}$ & $\$ 20$ \\
\hline $\begin{array}{l}\text { Phase IV - Advanced } \\
\text { development }\end{array}$ & $\begin{array}{l}\text { Active permitting and negotiations } \\
\text { Project design } \\
\text { Project financing } \\
\text { Equipment procurement } \\
\text { Ongoing issue resolution }\end{array}$ & $\$ 20-\$ 30$ \\
\hline
\end{tabular}

Table 3. Direct Cost Ranges Associated with Siting Considerations for a Typical 100-MW Wind Project (2013\$)

\begin{tabular}{lll}
\hline Siting Consideration Category & Standard Project & Higher-Cost Project \\
\hline Public Engagement & $\$ 1,319,000$ & $\$ 5,581,000$ \\
Wildlife & $\$ 1,623,000$ & $\$ 6,697,000$ \\
Radar & $\$ 30,000$ & $\$ 710,000$ \\
\hline
\end{tabular}

\subsubsection{Project Development Risk}

To better understand project development risk, we also asked development firms for insights on the percentage of projects that moved to each of the four development phases. Using those insights, we estimated that two to four times the cost of a single project may be required in indirect costs to deliver a single completed (commissioned) project. Examples of such costs include sunk investment costs in failed or stalled projects; the cost of maintaining facilities, staff, and a pipeline of projects even if none of them comes to fruition; and the costs required to redo studies as a result of project delays. These insights and data suggest a per project success rate of between $25 \%$ and $50 \%$ - a significant improvement from previous rates in the early 2000s, which were closer to $10 \%$, according to developers. 
With more data and the ability to track risk levels over time, several meaningful statistics could be derived that could direct research resources to the objective of lowering project development risk. Potential useful statistics or metrics include time to complete each development phase, probability of survival to the next phase, and probability of survival overall.

\subsection{Representations of Siting Considerations}

From the data collected, nine specific representations of siting considerations, including the "Standard" representation typically applied in NREL analysis (Lopez et al. 2012), were identified and developed for subsequent assessment and analysis. As noted in Section 2, cost adders and partial or full land exclusions were applied at varying levels to reflect approximate moderate and high siting difficulty for each siting consideration. Cost-adder representations were drawn from the direct cost data obtained from developers (Table 2 and Table 3 ) and were vetted by other industry experts, including researchers knowledgeable about a specific siting consideration's impact on wind power project development. The following subsections describe these specific representations at the categorical level; Table 4 (Section 3.2.5) details the specific costs and land availability characteristics for each of the nine specific representations. Notably, these representations are not intended to reflect precise siting designations, but rather they provide high-level indications of the potential magnitude that varied levels of land restriction and incremental cost may have on future wind deployment.

\subsubsection{Standard Representation}

The standard representation contains no cost adders or exclusions apart from standard exclusions used by NREL (Lopez et al. 2012). Standard exclusions include wetlands, urban areas, parks, forests, landmarks, and other non-developable areas. The Standard representation is used as a reference for comparing and understanding the effects of the additional siting representations.

\subsubsection{Radar Representation}

The FAA, the U.S. Department of Homeland Security, and the U.S. Department of Defense (DoD) assess the impacts of wind turbines on radar installations. Wind turbine towers can block radar signals and the spinning blades can cause signal interference. Agencies may require mitigation measures. Assessments and mitigation requirements are conducted and identified as part of the FAA's airspace obstruction evaluation process. Both the distance between the turbine and a radar station as well as the line-of-sight distance are important.

Scenarios in this analysis address three types of radar: weather radar, airport terminal radar, and long-range radar. We used the line-of-sight analysis from the Natural Resources Defense Council database for weather radar. ${ }^{11}$ We also received data from the DoD Clearinghouse ${ }^{12}$ on other types of radar, including air route surveillance radar,

\footnotetext{
${ }^{11}$ Renewable Energy and Defense (READ) Database, Version 1. (2011). Natural Resources Defense Council.

${ }^{12}$ DoD Siting Clearinghouse: http://www.acq.osd.mil/dodsc/.
} 
common air route surveillance radar, and other radar installations. Based on discussions with DoD, developers, and radar experts, we assume two different land area zones around radar stations where exclusions of potential wind power sites are applied: (1) 3 kilometers $(\mathrm{km})$ around the weather radars and (2) approximately $9 \mathrm{~km}$ around the DoD radars. In addition, for all radar facilities, the area $36 \mathrm{~km}$ around the radar facility is considered as an area that may be developed but would take additional negotiation and added costs. Within the exclusion zones ( $3 \mathrm{~km}$ around weather radars and approximately $9 \mathrm{~km}$ around DoD radars), $99 \%$ of the land is assumed to be unavailable for wind development, leaving a very low probability of development in the area; see Figure B-4 in Appendix B for a radar map. The additional 36-km "mitigation zone" results in added cost for radar mitigation at $\$ 3 / \mathrm{kW}$ in the moderate scenario and $\$ 7 / \mathrm{kW}$ in the high scenario.

\subsubsection{Wildlife Representation}

Wildlife represents another siting consideration for wind deployment. When developers and project owners consider pursuing a wind project at a site that is in the range of a species of concern (e.g., golden eagles, greater sage grouse), they work with the U.S. Fish and Wildlife Service and state agencies to conduct site-specific risk assessments for the wildlife of interest. Based on the results of these assessments, developers may be required to develop a habitat conservation plan or apply for a permit under the Endangered Species Act or Bald and Golden Eagle Protection Act. These steps can add to development time and cost. Actual costs to assess and mitigate impacts to sensitive species vary according to the unique circumstances on a project site.

To characterize the potential impacts of wildlife concerns as our high and moderate representations, we considered different degrees to which avian and bat species interaction could limit wind development. Informed by subject matter experts from the wind industry and wildlife conservation community, we grouped the avian and bat species of greatest concern into two impact types:

1. Species whose habitat is at risk of fragmentation, such as the greater prairie chicken (Tympanuchus cupido), lesser prairie chicken (Tympanuchus pallidicinctus), and greater sage-grouse (Centrocercus urophasianus)

2. Species at risk of air space interference, such as the Indiana bat (Myotis sodalist), northern long-eared bat (Myotis septentrionalis), little brown bat (Myotis lucifugus), tri-colored bat (Perimyotis subflavus), whooping crane (Grus americana), golden eagle (Aquila chrysaetos), and bald eagle (Haliaeetus leucocephalus). ${ }^{13}$

After grouping species, we made assumptions about the relative costs (due to the requisite studies, permits, and mitigation measures) that the presence of these species could add to a project. We also estimated the amount of land (habitat and breeding ground) that might prove too difficult to develop as a wind project site due to the presence of these species. Areas with cost adders are not meant to represent a particular

\footnotetext{
${ }^{13}$ Eagle risk is defined in the U.S. Fish and Wildlife Service Eagle Conservation Plan Guidance (U.S. Fish and Wildlife Service 2013).
} 
historical or projected scenario. Rather, the assumptions allow us to investigate the impact of a more constrained scenario (e.g., where wildlife issues may highly constrain wind development) compared to a less constrained scenario (e.g., where wildlife issues may moderately constrain wind development). Cost adders and "undevelopable" areas used to define these scenarios (Table 4) were developed from expert opinion.

\subsubsection{Public Engagement Representation}

Public engagement was the next siting consideration taken into account. Here we considered distance from residences as the primary potential issue for host communities and residents. For public engagement, we asserted a "no-build area" surrounding any group of three residences. In the moderate siting scenario, the distance was defined as $1,500 \mathrm{ft}$ (457 meters) from three or more residences. ${ }^{14}$ In the high (more difficult) siting scenario, the distance was set to $2,500 \mathrm{ft}$ (762 meters). The 1,500-ft and 2,500-ft distances are informal estimates of typical set-back distances that may be needed to satisfy local siting regulations. In actuality, many turbines are installed within $2,500 \mathrm{ft}$ of three residences. These distances do not represent a recommended distance but were chosen to understand the magnitude of potential no-build areas. For public engagement, a defined "mitigation area" is $500 \mathrm{ft}$ beyond the no-build areas. For the purposes of this analysis, placing turbines in the mitigation area was allowed, but doing so triggered additional costs.

\subsubsection{Combined Representations}

The "combined-moderate" representation combines each of the moderate versions of siting considerations. It was developed to represent a world where siting considerations moderately constrain wind project development, with accompanying cost adders and land restrictions. Similarly, we developed a "combined-high" scenario to represent a world where costs and land restrictions are higher.

\footnotetext{
${ }^{14}$ According to the feedback from developers (summarized in Section 3), if there are only one or two residences within the footprint of a potential wind farm, the developer could negotiate with the homeowners to purchase the residence or residences. With more than two residences, that case is less likely.
} 
Table 4. Summary of Cost Adder and Land Restrictions for Each Representation (2013\$)

\begin{tabular}{|c|c|c|c|c|}
\hline $\begin{array}{l}\text { Siting } \\
\text { Consideration }\end{array}$ & $\begin{array}{l}\text { Key Considerations } \\
\text { (Defining } \\
\text { Characteristics) }\end{array}$ & $\begin{array}{l}\text { Level of } \\
\text { Impact }\end{array}$ & $\begin{array}{l}\text { Land Unavailable for } \\
\text { Wind Energy } \\
\text { Deployment (\%) }\end{array}$ & $\begin{array}{l}\text { Cost } \\
\text { Adder } \\
\text { (\$/kW) }\end{array}$ \\
\hline Standard & $\begin{array}{l}\text { NREL standard } \\
\text { exclusions are applied. }\end{array}$ & Reference & $\begin{array}{l}\text { None after standard } \\
\text { exclusions }\end{array}$ & None \\
\hline \multirow{2}{*}{ Radar } & \multirow{2}{*}{$\begin{array}{l}\text { Area is restricted based } \\
\text { on proximity to weather, } \\
\text { airport, and long-range } \\
\text { radars. }\end{array}$} & Moderate & $\begin{array}{l}99 \% \text { of land within a } 3- \\
\mathrm{km} \text { radius of weather } \\
\text { radar or } 9.26-\mathrm{km} \text { radius } \\
\text { of DoD radar }\end{array}$ & $\$ 3$ \\
\hline & & High & $\begin{array}{l}99 \% \text { of land within larger } \\
\text { no-build zones, up to } 36 \\
\text { km incorporating line-of- } \\
\text { sight }\end{array}$ & $\$ 7$ \\
\hline \multirow[b]{2}{*}{ Wildlife } & \multirow{2}{*}{$\begin{array}{l}\text { Proximity to species at } \\
\text { risk of habitat } \\
\text { fragmentation (prairie } \\
\text { chicken, sage grouse) } \\
\text { and species at risk of air } \\
\text { space interference } \\
\text { (bats, whooping cranes, } \\
\text { eagles) }\end{array}$} & Moderate & $\begin{array}{l}60 \%-80 \% \text { of land within } \\
\text { affected area }\end{array}$ & $\$ 25-\$ 55$ \\
\hline & & High & $\begin{array}{l}75 \%-90 \% \text { of land within } \\
\text { affected area }\end{array}$ & $\$ 25-\$ 55$ \\
\hline \multirow{2}{*}{$\begin{array}{l}\text { Public } \\
\text { Engagement }\end{array}$} & \multirow{2}{*}{$\begin{array}{l}\text { Proximity to community } \\
\text { with at least three } \\
\text { residences }\end{array}$} & Moderate & $\begin{array}{l}100 \% \text { of land within } 1,500 \mathrm{ft} \\
(457 \mathrm{~m}) \text { of community }\end{array}$ & $\begin{array}{l}\$ 25(1,500 \mathrm{ft} \\
{[457 \mathrm{~m}] \text { to }} \\
2,000 \mathrm{ft}[610 \\
\text { m] radius })\end{array}$ \\
\hline & & High & $\begin{array}{l}100 \% \text { of land within } 2,500 \mathrm{ft} \\
(762 \mathrm{~m}) \text { of community }\end{array}$ & $\begin{array}{l}\$ 50(2,500 \mathrm{ft} \\
{[762-\mathrm{m}] \text { to }} \\
3,000 \mathrm{ft} \\
{[914-\mathrm{m}]} \\
\text { radius })\end{array}$ \\
\hline $\begin{array}{l}\text { Combined } \\
\text { Moderate }\end{array}$ & $\begin{array}{l}\text { Radar + Wildlife + Public } \\
\text { Engagement }\end{array}$ & \multicolumn{3}{|c|}{ Combination of all moderate scenarios } \\
\hline Combined High & $\begin{array}{l}\text { Radar + Wildlife + Public } \\
\text { Engagement }\end{array}$ & \multicolumn{3}{|c|}{ Combination of all high scenarios } \\
\hline
\end{tabular}

a $9.26 \mathrm{~km}$ is equivalent to 5 nautical miles, which is the unit of measure used by DoD radar locations and wind turbines. 


\subsection{Geographic Information System (GIS) Analysis}

After constructing the representations, we developed GIS layers for each consideration and estimated the impact on developable land area. For the purposes of this analysis, developable land area was defined as area capable of producing a levelized cost of energy (LCOE) below $\$ 97 /$ megawatt-hour (MWh) based on 2013 technology and pricing. This threshold is consistent with the wind resource potential represented in Wind Vision and reflects locations that may be developable either today or in the future with continued cost reductions. Prior to any analysis of the additional siting considerations evaluated in this project, the land-based wind resource data were filtered to exclude areas considered unlikely to be developed for either legal or technical reasons. These exclusions areas, which are included in the Standard representation, include national parks, wilderness areas, wildlife refuges, urban areas, airports, steep slopes, and 50\% of forested land (Lopez et al. 2012).

Figure 2 shows the developable wind resource after the standard considerations were applied. The wind resource is categorized into five techno-resource groups (TRGs) $)^{15}$ (DOE 2015), with TRG1 representing the highest-quality resource and TRG5 representing the lowest-quality resource. The TRGs are determined based on the quality of the wind resource and the assumed turbine technology, which are used to characterize a site-specific LCOE. Base-year costs for delivered electricity range from approximately $\$ 51 / \mathrm{MWh}$ in higher wind resource areas in TRG1 to $\$ 85 / \mathrm{MWh}$ for lower wind resource areas in TRG5 for land-based wind. As indicated above, the underlying wind resource characterization used in this analysis is consistent with that described and detailed in Wind Vision (DOE 2015). Notably, however, this analysis does not include the opportunity for expanded resource potential highlighted in DOE's recent report, Enabling Wind Power Nationwide (Zayas et al. 2015). ${ }^{16}$
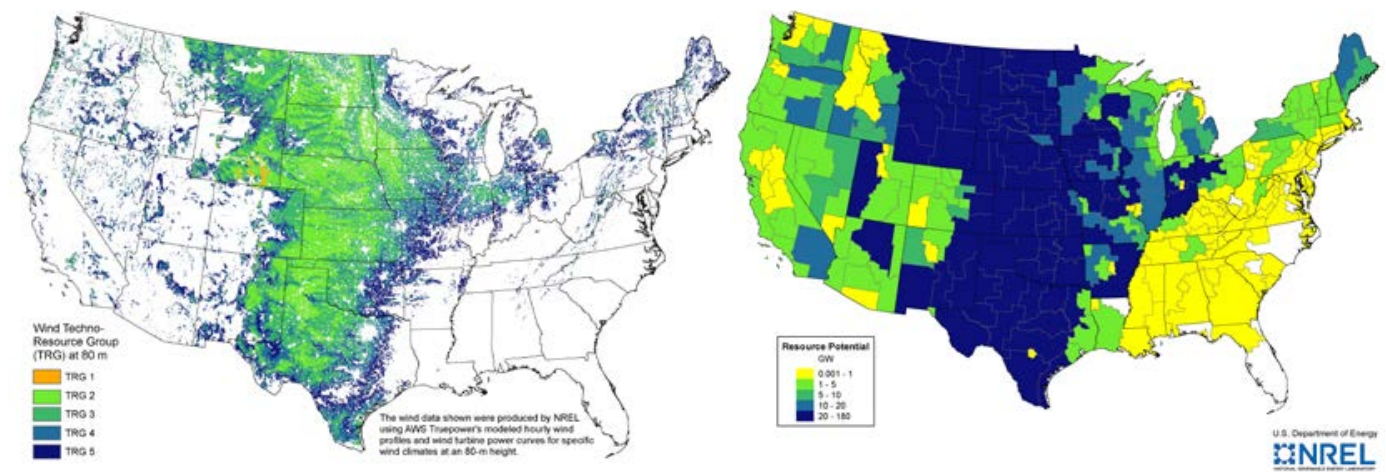

Figure 2. Developable land-based wind resource in the United States, quality by technoresource group (left) and quantify (right), based on standard exclusions

\footnotetext{
${ }^{15}$ For more on the TRGs, see Appendix H of Wind Vision (DOE 2015).

${ }^{16}$ Including this expanded resource could provide the opportunity to mitigate some of the siting challenges; however, the economic viability of development using such technologies has yet to be comprehensively assessed in the United States.
} 
Figure 3 shows the siting consideration layers for the combined-moderate representation. Figure 4 shows the siting consideration layers for the combined-moderate high representation. Additional maps of wildlife habitat, migratory corridors, potential radar issues, and public engagement representations can be reviewed in Appendix B; a map illustrating the coincidence of federal lands and the wind resource potential is included in Appendix C. ${ }^{17}$ These maps indicate that the majority of the United States is likely to be affected by one or more of the siting considerations examined in this study.

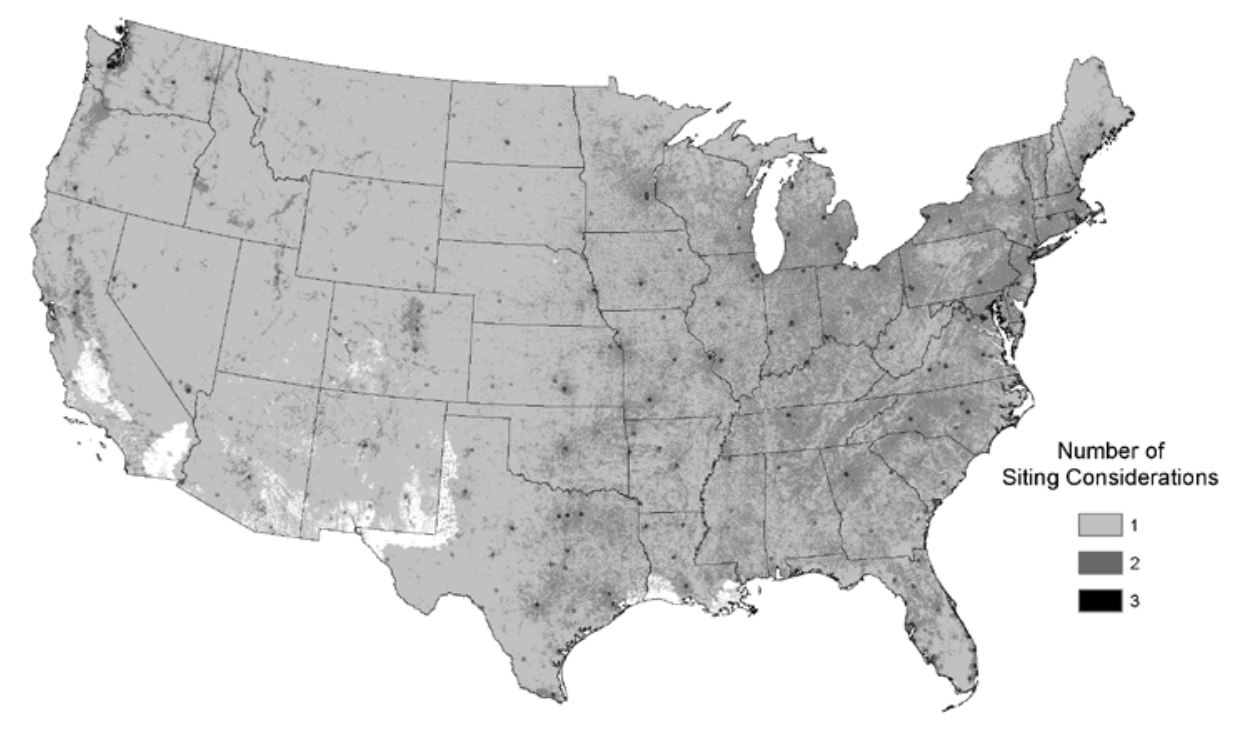

Figure 3. Map of the United States showing an aggregation of the moderate siting consideration representations

\footnotetext{
${ }^{17}$ After interviewing developers about the wildlife-related project risks they encounter, particularly on federal lands, we added a map of the U.S. wind resource at $80 \mathrm{~m}$ with federal lands overlaid. Including federal lands illustrates where and how much federally owned land intersects with the wind resource. Although federal lands do not preclude wind development, no wind development was occurring on federal lands at the time of this analysis, and developers did not seem optimistic that permitting on federal lands would become easier in the short term.
} 


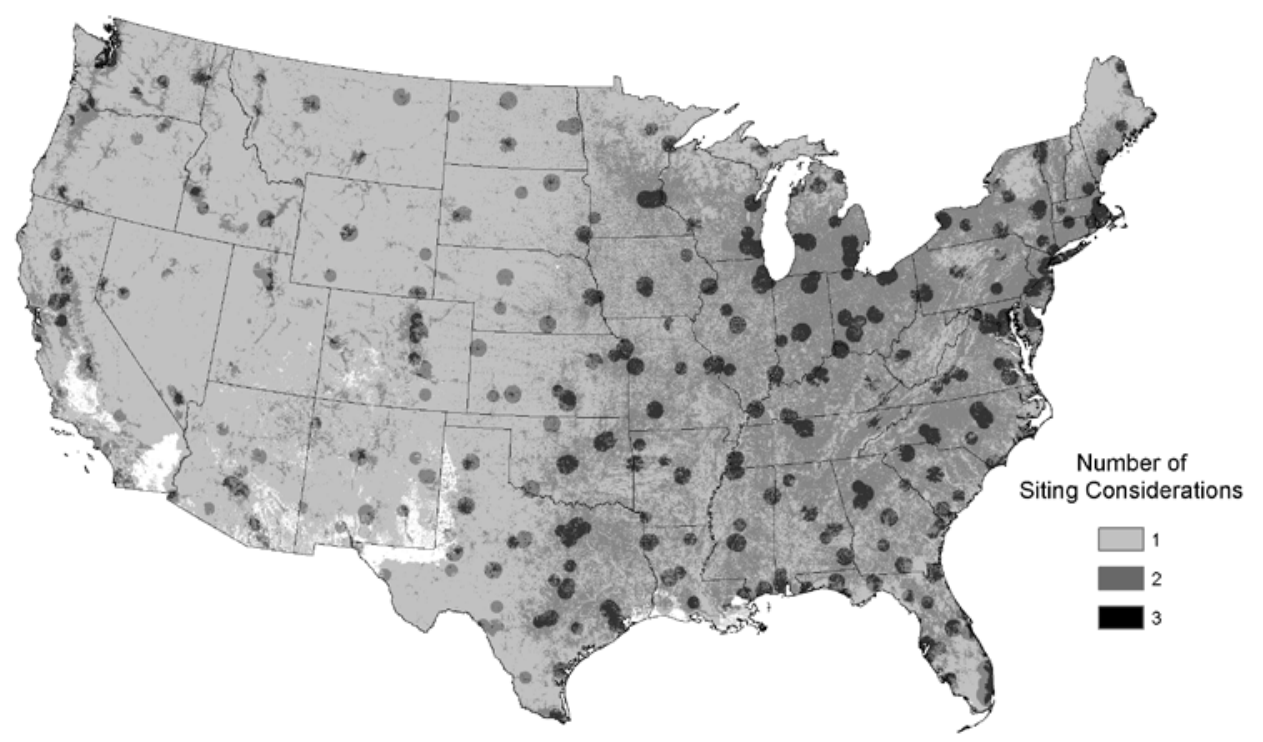

Figure 4. Map of the United States showing an aggregation of the high siting consideration representations

Importantly, the maps in Figures 3-4 do not represent areas where wind development should be restricted. On the contrary, the maps represent simplistic spatial trends in how and where specific siting considerations could pose concerns to wind power project development. Moreover, these areas are not absolute. For this specific analysis, only a percentage of the affected land area represented in the maps may be considered not developable based on the specific exclusion percentages noted in Section 3.2. Also, there is clear empirical evidence that wind turbines may be sited in areas where siting considerations exist. As a single example, Iowa turbines have been installed in areas within 2,500 ft (762 meters) of three or more residences. This suggests that the simplified representations illustrated here may be more stringent than historical evidence supports. As well, the specific siting constraints and their stringency in any given location will vary as a function of local conditions and considerations. In spite of these caveats, these maps can be considered illustrative of the broad reach of the siting considerations and the additional risks wind developers incur when they pursue development in these regions.

Moving to quantitative assessments, Table 5 shows the change in developable wind resource capacity when applying the specific siting consideration representations. Results are broken out by TRG to illustrate the degree to which lower- or higher-quality resource sites may be affected. These data indicate that because the United States has an abundant wind resource, the United States could technically reach the levels of deployment in DOE's Wind Vision (20\% wind energy by 2030 and 35\% wind energy by 2050 ) even if estimates of developable capacity were reduced by half. 
Table 5. Impact of Siting Considerations on Developable Area (Capacity) of Wind Vision by TRG

\begin{tabular}{|c|c|c|c|c|c|c|}
\hline $\begin{array}{l}\text { TRG } \\
2013 \text { LCOE }\end{array}$ & $\begin{array}{l}\text { TRG1 \$51/MWh } \\
\text { (GW) }\end{array}$ & $\begin{array}{l}\text { TRG2 \$55/MWh } \\
\text { (GW) }\end{array}$ & $\begin{array}{l}\text { TRG3 \$61/MWh } \\
\text { (GW) }\end{array}$ & $\begin{array}{l}\text { TRG4 \$72/MWh } \\
\text { (GW) }\end{array}$ & $\begin{array}{l}\text { TRG5 \$85/MWh } \\
\text { (GW) }\end{array}$ & $\begin{array}{l}\text { Quantity of } \\
\text { Standard } \\
\text { Resource } \\
\text { Affected }\end{array}$ \\
\hline Standard & 70 & 1,171 & 2,429 & 1,175 & 1,323 & -- \\
\hline Moderate Wildlife & 28 & 444 & 978 & 558 & 734 & $56 \%$ \\
\hline High Wildlife & 17 & 271 & 596 & 341 & 440 & $73 \%$ \\
\hline $\begin{array}{l}\text { Moderate Public } \\
\text { Engagement }\end{array}$ & 70 & 1,133 & 2,291 & 1,032 & 1,280 & $6 \%$ \\
\hline $\begin{array}{l}\text { High Public } \\
\text { Engagement }\end{array}$ & 68 & 1,072 & 2,130 & 909 & 1108 & $14 \%$ \\
\hline Moderate Radar & 69 & 1,160 & 2,405 & 1,163 & 1,310 & $1 \%$ \\
\hline High Radar & 65 & 1,115 & 2,315 & 1,152 & 1,284 & $4 \%$ \\
\hline Combined Moderate & 27 & 413 & 879 & 444 & 522 & $63 \%$ \\
\hline Combined High & 15 & 229 & 474 & 240 & 268 & $80 \%$ \\
\hline
\end{tabular}

LCOEs shown for the Standard representation are (1) capacity-weighted averages for all potential sites in each TRG and (2) based on estimated 2012 and 2013 technology and project costs. Groups categorize sites based on how selected turbines would perform at different sites. For more information, refer to Wind Vision (DOE 2015). In addition, "developable" potential reflected here should be distinguished from other estimates of gross or technical potential, as it reflects both the standard exclusions or siting considerations noted in Lopez et al. (2012) and an LCOE floor of \$97/MWh using commercially available technology and costs, of 2012 and 2013 vintage. 
Within the context of the quantitative assessment by TRG, it is important to note that all land is not the same in the eyes of wind project developers. Land restricted to development by radar or an avian species in less windy areas (or in areas with poor access to transmission or less favorable market conditions) should be of less concern than areas off limits for development in better wind resource areas. Similarly, not all siting considerations impact the highest wind resource areas equally (Figure 5). In particular, we find that wildlife habitats have the greatest overlap with areas of high wind resource quality (i.e., TRG1 and TRG2). Notwithstanding these caveats, for planners and decision makers seeking to allow for responsible renewable energy development, areas with relatively high-quality resources and relatively fewer siting considerations (e.g., unaffected high-quality resource areas illustrated above) could be targeted to reduce project development risk.

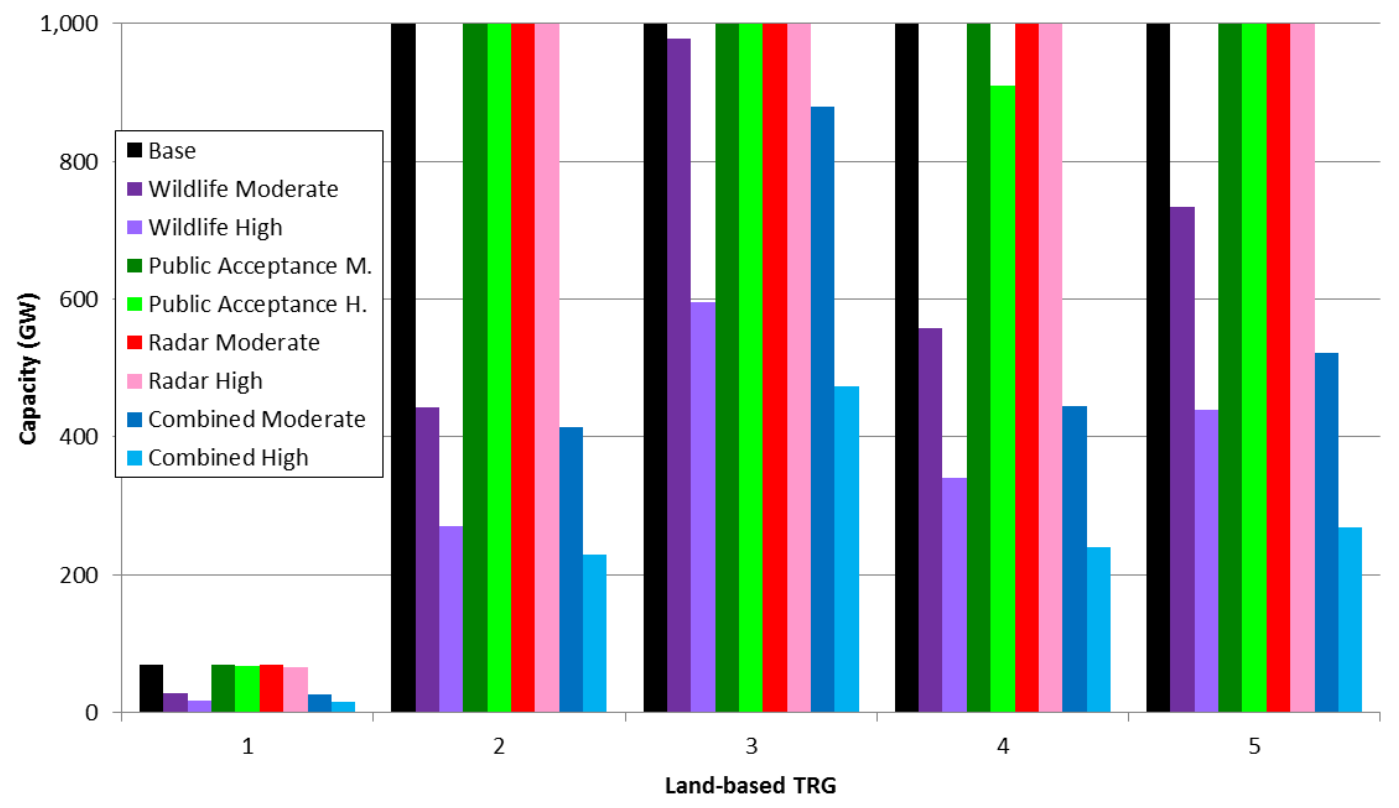

Figure 5. Histogram of impact on available capacity by TRG (first 1,000 GW in each TRG)

Focusing on the cost-adder portion of the siting consideration representations, Figure 6 shows the incremental LCOE for the combined moderate and high siting considerations, relative to the Standard wind resource representation. The incremental cost associated with moderate or high siting restrictions reaches \$15-\$20/MWh for wind capacity of 300-500 GW; such quantities have been associated with annual energy production of 20\%-35\% in prior studies (DOE 2006; NREL 2012; DOE 2015). ${ }^{18}$ As more wind power capacity is installed, the potential cost increases associated with siting considerations could partially offset expected reductions in cost related to technology improvements over time.

\footnotetext{
${ }^{18}$ LCOE impacts shown in Figure 6 reflect potential higher costs at a particular site as well as the shift in resources toward lower-quality wind sites when additional land exclusions are applied.
} 


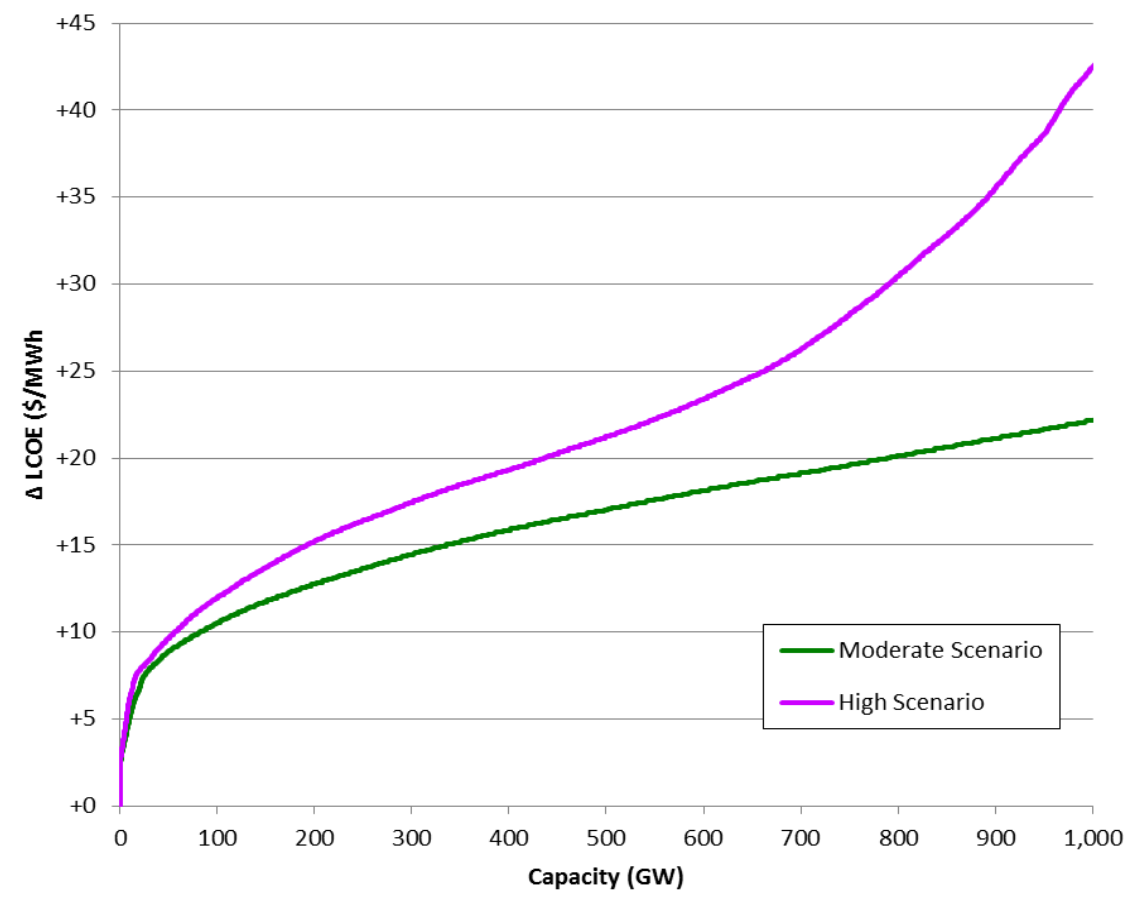

Figure 6. Incremental cost for the first $1,000 \mathrm{GW}$ of developable wind potential, based on the combined moderate and high siting consideration representations

\subsection{ReEDS Deployment Modeling Results}

Figure 7 illustrates the impacts of combined moderate and high siting considerations and the post-2020 interregional transmission exclusion on the BAU scenario results. The main impact of adding siting considerations to the BAU deployment is a reduction of wind capacity deployed that is due to the additional land area restrictions and incremental costs. Both siting considerations and transmission restrictions have a limited effect on the short-term deployment of wind; all scenarios deploy between $99 \mathrm{GW}$ and $116 \mathrm{GW}$ of land-based wind by 2030. However, the differences are more pronounced by 2050 .

Under the combined moderate level of siting considerations for radar, wildlife, and public engagement (BAU-Moderate), 2050 land-based wind capacity is estimated at $245 \mathrm{GW}$. In the BAU-High scenario, 2050 wind capacity is estimated to be lower at $202 \mathrm{GW}$. In these cases, wind is estimated to serve 21\% (BAU-Moderate) and 18\% (BAU-High) of end-use demand in 2050. In comparison, the BAU-Standard scenario results in $280 \mathrm{GW}$ of wind by 2050 , serving $24 \%$ of end-use demand. Reductions in capacity that are driven by siting consideration occur across all TRGs but are particularly noticeable in TRG1 and TRG3 (Figure 8).

Restricting new transmission post-2020 alone reduces cumulative long-term wind deployment, with an effect comparable in magnitude to the combined moderate siting considerations. More specifically, the impact of disallowing new interregional transmission reduces wind capacity by $25 \mathrm{GW}$ in 2050 relative to the BAU-Standard conditions, while a reduction of $35 \mathrm{GW}$ is estimated to be caused by the moderate siting considerations. Restricting transmission is estimated to have an additive effect with the 
other siting considerations (Figure 7), but the incremental effects of restricting transmission in 2050 wind capacity are similar for the BAU-Moderate (by $35 \mathrm{GW}$ ) and BAU-High scenarios (by $33 \mathrm{GW}$ ). Notably, however, transmission restrictions are found to disproportionately impact the deployment of relatively higher wind quality resource bins (mainly TRG2 and TRG3), and in certain cases, can shift wind deployment toward lower-quality resources (TRG4 and TRG5). Geographically, the modeled reductions in 2050 wind capacity are concentrated in the Midwest and, to a lesser degree, the Pacific Northwest.
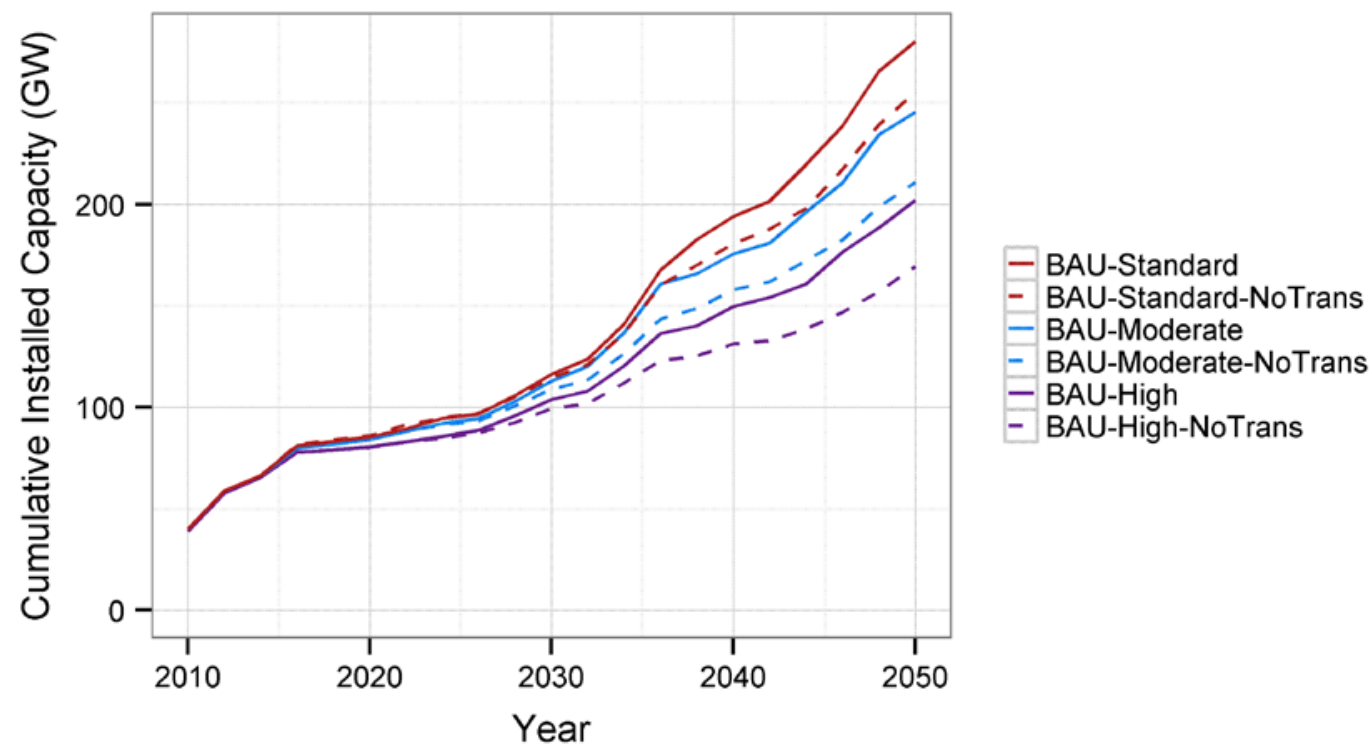

Figure 7. Land-based wind capacity deployment projections for the BAU scenarios

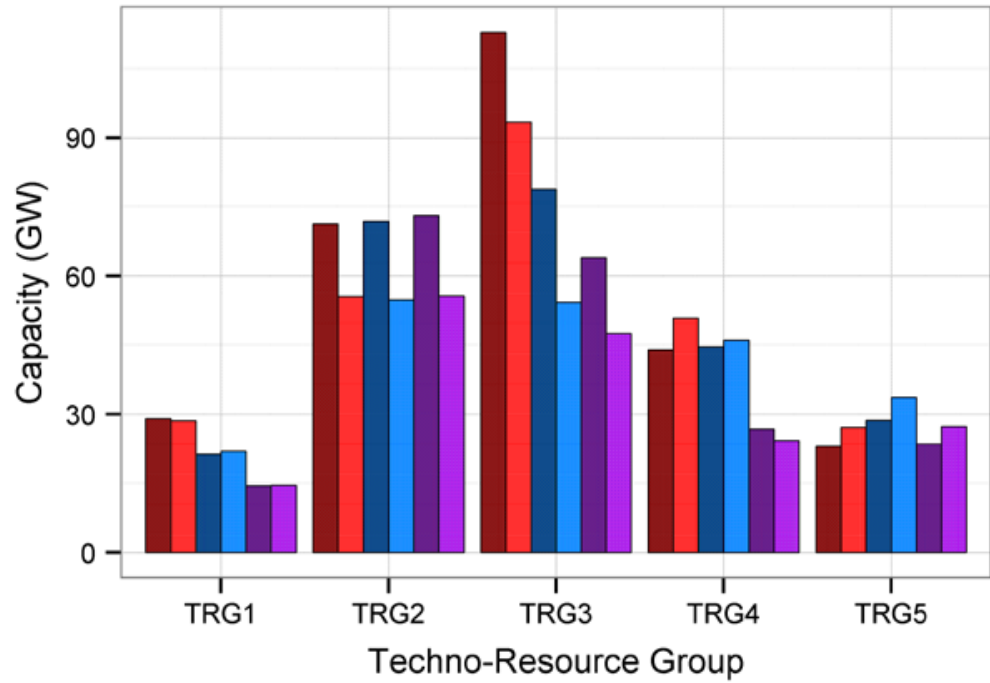

BAU-Standard

BAU-Standard-NoTrans

BAU-Moderate

BAU-Moderate-NoTrans

BAU-High

BAU-High-NoTrans

Figure 8. Land-based wind capacity deployment by TRG for the BAU scenarios by 2050 
Under the BAU scenarios, modeled siting considerations are estimated to have a small impact on national average retail electricity prices and total system costs. ${ }^{19}$ Retail electricity prices in 2050 are estimated to vary between $\$ 120 / \mathrm{MWh}$ and $\$ 124 / \mathrm{MWh}$ across all BAU scenarios. Comparing the scenario with the most restrictions and costs added to wind deployment, BAU-High-No Trans, with the BAU-Standard scenario results in incremental 2050 prices of $\$ 4 / \mathrm{MWh}(3 \%)$ and a net present value (NPV) of total system costs increase of $2.3 \%$. These higher costs are the result of cost adders applied to wind directly from siting consideration representations as well as greater reliance on otherwise more-expensive wind and non-wind electricity generation to serve demand.

Although costs are higher for these scenarios, their magnitude is small (3\% or less). This suggests siting considerations are causing a portion of wind capacity to become less economic in the long term, but that the system replaces that capacity and energy with resources that are similarly priced. Notably, these costs do not represent the costs to overcome barriers associated with wind power plant siting. Instead, these costs reflect changes in wind deployment and other electric-sector impacts associated with cost adders and developable land applied to reflect the siting considerations modeled (e.g., radar, wildlife, and public engagement).

In addition to the BAU scenarios, we estimated the impact of siting considerations for the Study Scenario family of scenarios, all of which followed the same prescribed wind penetration levels: $20 \%$ of end-use demand by 2030 and $35 \%$ by 2050 . In this way, all the Study scenarios were forced to reach the same level of energy generated from wind. However, the installed wind capacity needed to meet these levels and the geographic distribution of this capacity can and do differ. In particular, the installed wind capacity required to produce the specified amount of energy increased when siting considerations exclude access to higher-quality wind resources and thus increase reliance on lower capacity factor wind.

Figure 9 represents the evolution of land-based capacity for all Study Scenario outcomes. Installed 2030 land-based wind capacity is similar in all cases (i.e., largely insensitive to siting considerations), ranging from $202 \mathrm{GW}$ to $211 \mathrm{GW}$ (Figure 9). This small range indicates that under this timeframe and at this level of deployment, the modeled siting considerations have little impact on the amount of wind capacity needed to meet the $20 \%$ by 2030 level considered in Wind Vision.

\footnotetext{
${ }^{19}$ System costs include all capital, operation and maintenance, and fuel costs for generation and transmission accumulated from 2015 to 2050 , using a $3 \%$ discount rate.
} 


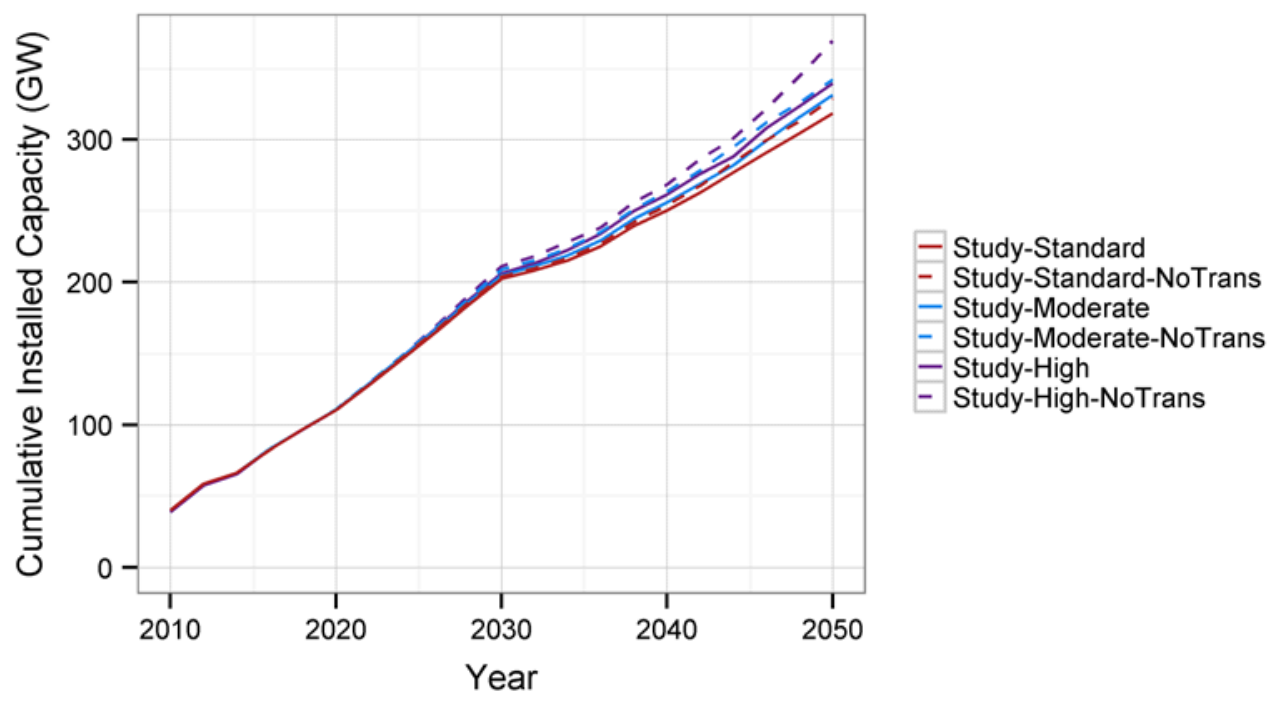

Figure 9. Land-based wind capacity deployment projections for the Wind Vision Study scenarios

In 2050, differences in installed land-based wind capacity needed to meet Study Scenario wind energy requirements grow. For example, we estimate that $318 \mathrm{GW}$ of land-based wind capacity is deployed by 2050 in the Study-Standard scenario ${ }^{20}$ compared with $331 \mathrm{GW}$ in the Study-Moderate and $339 \mathrm{GW}$ in the Study-High scenarios. The greater required capacity indicates that increased stringency in the siting considerations would cause higher reliance on lower-quality wind sites and greater wind curtailments to achieve the 2050 wind penetration levels envisioned. For example, under the StudyStandard scenario, $12 \%$ of all 2050 land-based wind capacity was deployed in the TRG with the best wind resource and 6\% in the lowest TRG, whereas under the Study-High scenario, only $7 \%$ was deployed in the best TRG and $16 \%$ in the lowest TRG. Similarly, curtailment rose from 39 terawatt-hours (TWh) (4\% of available land-based wind generation) to $68 \mathrm{TWh}$ ( $8 \%$ of available land-based wind generation), across the same two scenarios. The siting considerations changed the geographic distribution of wind deployed under the Study scenarios, primarily by reducing wind capacity in the upper Midwest and increasing wind deployment in the Southeast. ${ }^{21}$

Focusing on the impacts of a complete restriction on interregional transmission expansion post-2020 on reaching the Wind Vision penetration levels under the most extreme conditions modeled-where "high" siting considerations for radar, wildlife, and public engagement are combined with the restriction on interregional transmission expansionReEDS modeling indicates that 35\% wind penetration by 2050 is feasible. However, we find that an additional $51 \mathrm{GW}$ of land-based wind (relative to the Study-Standard scenario) are needed by 2050 to meet this penetration level. Increased levels of installed

20 This is the same as the Central Study Scenario from Wind Vision.

${ }^{21}$ This trend suggests that advanced wind technologies such as taller towers or larger rotor diameters could potentially help mitigate impacts of siting challenges on wind deployment in the United States (Zayas et al. 2015). 
wind capacity are a consequence of greater reliance on lower-quality wind resources and additional curtailment, both of which are amplified as regional collaboration and interregional balancing of wind are constrained by the limit on transmission expansion. Notably, however, transmission restrictions have more limited impacts on incremental installed wind capacity needed under the Study-Standard and Study-Moderate scenarios. 2050 reductions in these two scenarios are estimated to be $11 \mathrm{GW}$ relative to the corresponding "No Trans" scenarios, compared to $30 \mathrm{GW}$ between the Study-High-No Trans and Study-High scenarios.

Figure 10 shows the average retail electricity prices across all Study scenarios. Electricity prices in 2030 are largely unaffected by the siting considerations; even under the most stringent conditions, 2030 electricity prices increase by less than $\$ 1 / \mathrm{MWh}$ relative to the Study-Standard scenario. The effects of siting challenges are larger in 2050. When new interregional transmission expansion is allowed, the 2050 electricity price is estimated to be $\$ 3.50 / \mathrm{MWh}$ higher in the Study-High scenario than it is in the Study-Standard scenario. Even higher electricity prices are estimated when new interregional transmission is restricted. Restricting new transmission expansion under the Combinedhigh siting consideration case yields 2050 electricity prices that are $\$ 6.50 / \mathrm{MWh}$ higher than in the Study-Standard scenario. Similar trends are found for NPV of electric system expenditures. When new interregional transmission expansion is allowed, the NPV of system cost increases by $1 \%$ and $2 \%$ for the moderate and high siting considerations scenarios, relative to the standard scenario. In the most extreme case where new longdistance transmission is restricted and combined with high siting considerations, NPV costs increase by $4 \%$ relative to the Study-Standard scenario.

As noted previously for the BAU scenarios, the estimated higher costs found in the Study scenarios do not represent the costs to overcome barriers associated with wind power plant siting. Instead, these costs reflect changes in wind deployment and other electricsector impacts associated with cost adders and developable land applied to reflect the siting considerations modeled (radar, wildlife, and public engagement). Implications that these incremental prices and system costs might have on the findings of Wind Vision (2015) are presented in Section 3.5. 


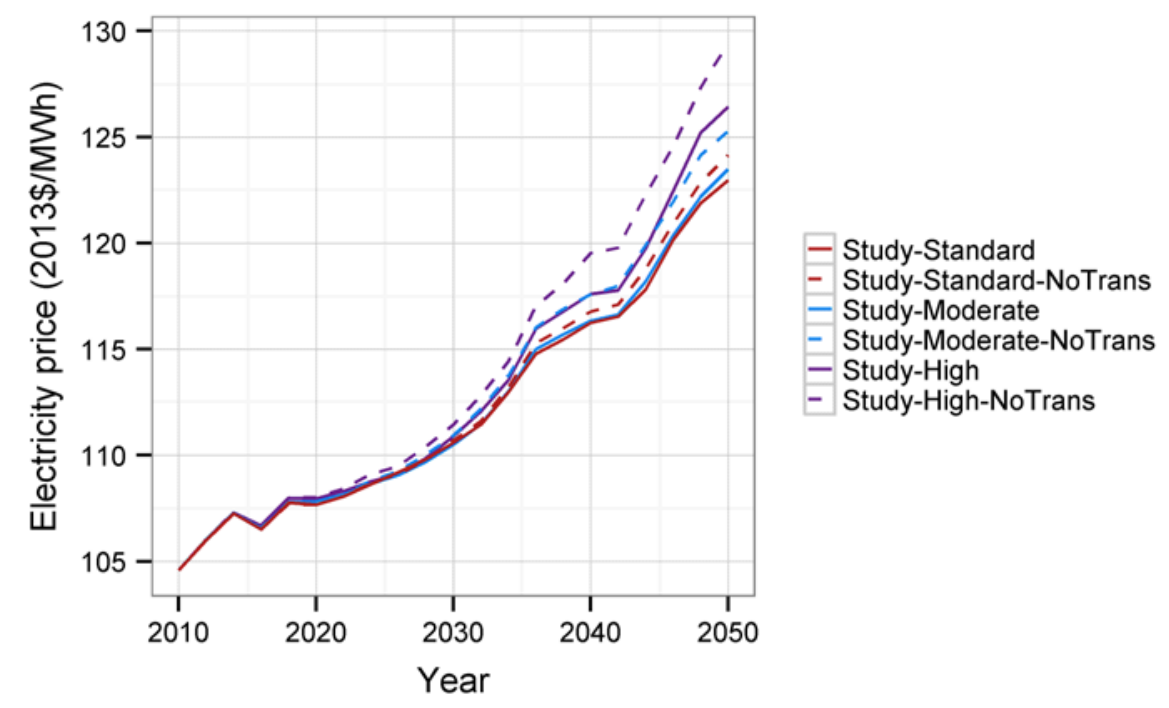

Figure 10. Average electricity price projections for Wind Vision Study scenarios

Notwithstanding these results, we note that ReEDS and other long-term capacity expansion models do not model all phases and accompanying risks of wind development. For example, hidden costs associated with failed projects and other issues described in Section 1 are not explicitly modeled. In addition, ReEDS is a system-wide optimization model that does not consider all local decision-making factors. As a consequence, the impact of siting considerations on future wind and other infrastructure, deployment is likely understated in ReEDS. Nonetheless, our modeling analysis provides a selfconsistent framework for evaluating the impacts of increased land exclusions and higher costs to wind project development at a national scale. 


\section{Implications for Wind Vision}

As noted in Section 2 and Section 3, this work represents an expansion of analysis initially conducted in the DOE Wind Vision (DOE 2015). In addition, it uses the same modeling methods, data, and some of the same scenarios as those originally studied in Wind Vision. In Wind Vision, the scenario modeling analysis was designed to evaluate the costs and benefits of achieving wind penetration levels (including both land-based and offshore) of $10 \%$ by $2020,20 \%$ by 2030 , and $35 \%$ by 2050 . In this section, we describe how the siting considerations for land-based wind energy deployment-as modeled and considered in the present analysis - might impact some of the key conclusions from Wind Vision. We do not attempt to complete a full re-analysis of Wind Vision, but instead point to directional or qualitative changes. Where possible, we use quantitative estimates from Section 3.4 and compare them with those published in Wind Vision. Key differences in the analysis structure and uncertainties are noted.

The cost, benefit, and impact assessments conducted for Wind Vision rely on a comparison of two primary scenarios: (1) the previously described Study Scenario (which is equivalent to the Study-Standard scenario described here) with predetermined wind penetration levels and (2) a Baseline scenario where U.S. installed wind capacity is fixed at 2013 levels $(61 \mathrm{GW})$ for all years. Notably, the Baseline scenario differs significantly from the BAU scenarios under which wind deployment model decisions are based on economics. Using the Baseline Scenario in Wind Vision allows for estimated costs and benefits associated with all new (post-2013) wind deployment instead of incremental (to BAU) wind deployment.

Relative to this no-new-wind Baseline, Wind Vision estimated incremental electricity prices and electric system costs of the Study Scenario (see Table 6 "Study Standard" results). Wind Vision found that under central assumptions, ${ }^{22}$ estimated 2020 and 2030 electricity prices were 0.06 cents/kWh and 0.03 cents $/ \mathrm{kWh}$ higher in the Study Scenario compared to the Baseline. By 2050, however, lower electricity prices $(0.28$ cents $/ \mathrm{kWh})$ were found in the Study Scenario as compared to the no-new-wind Baseline. In fact, the greater long-term savings were found to outweigh the nearer-term costs such that on an NPV basis (using a 3\% social discount rate), 2015-2050 electric system expenditures were found to be $\$ 149$ billion (-3\%) lower in the Study Scenario than in the no-new-wind Baseline. Wind Vision also uses sensitivity scenarios - associated with fossil fuel price and wind technology advancements - to estimate wider ranges of costs and savings than can be found in Wind Vision (DOE 2015).

As described in Section 3.4, the application of cost adders and exclusions to reflect siting considerations associated with radar, wildlife, and public engagement changed the estimated electricity prices and system costs for the Study Scenario (Table 6). Relative to the Wind Vision Baseline Scenario and without considering transmission limitations, we find that the modeled siting considerations would raise 2030 incremental prices by up to 0.06 cents/kWh under the most severe siting conditions. In 2050, savings would be

${ }^{22}$ The present analysis uses the same central assumptions of Wind Vision. 
reduced to 0.23 cents $/ \mathrm{kWh}$ under the Study-Moderate scenario, as compared to 0.28 cents/kWh under the Study-Standard scenario (and observed in DOE 2015), while the Study-High scenario would result in increased electricity rates, relative to the Wind Vision Baseline of 0.07 cents/kWh in 2050 . Under scenarios where post-2020 transmission is restricted, we find that relative to the Wind Vision Baseline Scenario the modeled siting considerations would raise 2030 incremental prices by up to 0.12 cents/kWh under the Study-High-No Trans scenario. In 2050, savings would be reduced to 0.16 cents $/ \mathrm{kWh}$ for the Study-Standard-No Trans scenario and 0.05 cents $/ \mathrm{kWh}$ under the Study-Moderate-No Trans scenario. In 2050, the Study-High-No Trans scenario would result in increased electricity rates, relative to the Wind Vision Baseline Scenario of 0.37 cents $/ \mathrm{kWh}$ in 2050. Similarly, we find that savings in present value of system expenditures relative to the Wind Vision no-new-wind Baseline would remain, but at a somewhat lower value (\$113 billion and $\$ 43$ billion vs. $\$ 149$ billion), under the Study-Moderate and Study-High scenarios. For the Study-High-No Trans scenario, the present value of system expenditures metric results in a net cost of $\$ 44$ billion (2013\$), fully eliminating the savings estimated in the Wind Vision Central Study Scenario, which did not consider a transmission-constrained future.

Table 6. Change in Retail Electricity Rates and Cumulative (NPV) of Electric-Sector Expenditures, Relative to the Wind Vision Baseline Scenario ${ }^{a}$

\begin{tabular}{|c|c|c|c|}
\hline & \multicolumn{2}{|c|}{ Retail Electricity Rates (Cents/kWh) } & \multirow{2}{*}{$\begin{array}{l}\text { Cumulative NPV of } \\
\text { Electric-Sector } \\
\text { Expenditures } \\
\text { (Billions of Dollars) } \\
2013-2050\end{array}$} \\
\hline & 2030 & 2050 & \\
\hline Study Standard ${ }^{b}$ & 0.03 & -0.28 & -149 \\
\hline Study Moderate & 0.02 & -0.23 & -113 \\
\hline Study High & 0.06 & 0.07 & -43 \\
\hline Study Standard-No Trans & 0.04 & -0.16 & -108 \\
\hline Study Moderate-No Trans & 0.07 & -0.05 & -59 \\
\hline Study High-No Trans & 0.12 & 0.37 & 44 \\
\hline
\end{tabular}

a Negative values indicate a savings relative to the Wind Vision Baseline Scenario; positive values indicate added costs.

b The "Study Standard" scenario is equivalent to the Wind Vision Central Study Scenario.

On the surface, these findings indicate that heightened siting considerations could reduce, or in combination with limits on future transmission development, potentially eliminate the long-term economic savings that a high-wind future might offer compared to one without any additional wind energy in the United States. However, these results need to be compared with other results from Wind Vision for more complete conclusions to be drawn. First, Wind Vision reports a wide range of possible incremental costs and savings, with possible NPV electric system savings of up to $\$ 388$ billion and incremental costs of up to $\$ 254$ billion depending on difficult-to-predict future fossil fuel prices and wind technology advancements. The impact of the siting considerations falls within this wide 
range. Second, Wind Vision also reports a large number of benefits associated with achieving the envisioned penetration levels relative to the no-new-wind Baseline Scenario. These benefits include $\$ 85$ billion- $\$ 1,230$ billion in avoided damages associated with global greenhouse gas emissions, $\$ 52$ billion- $\$ 272$ billion in avoided damages associated with other air pollutants, and significant reductions in electric-sector water use. We do not expect the siting considerations to significantly degrade any of these estimated benefits; siting considerations are estimated to impact the amount and distribution of wind capacity needed to reach the 35\%-by-2050 wind penetration level, but avoided generation and emissions are likely to be very similar to those estimated in Wind Vision. Finally, the comparisons made above rely on scenario design where siting considerations are applied to future wind development only. Applying these considerations more consistently across all generating technologies could further alter results and increase estimated costs in the Baseline Scenario. Thus, the impacts of siting considerations on the incremental costs of the Study scenarios relative to the Baseline Scenario should be treated as an upper bound.

In summary, when comparing the results of the current work to those in Wind Vision, we find that siting considerations could result in greater price increases in 2020 and 2030 (e.g., 0.06 cents/kWh for the Study-High scenario and 0.03 cents/kWh in 2030 for the Study-Standard scenario) but that long-term savings remain sufficient to drive cumulative NPV savings so long as the siting considerations studied here are not coupled with additional transmission constraints. With transmission constraints and the most stringent ("High") siting considerations, we find a cumulative NPV cost is incurred, but it remains within the larger range of potential cumulative costs or savings identified in Wind Vision as a function of differences in fossil fuel prices and wind technology costs. When considered relative to the societal benefits also quantified in Wind Vision and summarized above, the potential electric-sector costs associated with resolving these siting considerations and transmission restrictions, even while achieving 35\% wind energy by 2050 , remain a fraction of the societal value offered by wind power. 


\section{Conclusions and Future Research}

Given existing and planned wind projects, we know that it is possible for stakeholders to find ways for wind energy to coexist with affected wildlife and human uses. However, there has been limited public analysis of the potential level of impact that siting considerations are having on wind development and even fewer efforts to ascertain how they might affect future deployment.

As an initial effort to characterize the impacts of siting considerations including radar, public engagement, and wildlife species on U.S. wind power, this work consists of multiple facets. Insights on the development process and interactions between siting considerations and wind projects, including potential cost impacts were collected from semi-structured interviews with wind project developers and industry consultants. Data from these interviews were subsequently used to inform national representations of siting considerations and to assess potential overlaps with wind resource potential. Analysis of long-term impacts was conducted using long-term electric-sector capacity expansion modeling building from work completed in Wind Vision.

From data and insights gathered through semi-structured interviews and conducted in 2012 and 2013 as well as examination of existing and planned wind projects, we find that the development process provides several opportunities for consideration of siting issues. In fact, siting considerations may be raised and addressed at nearly every stage of the project development life cycle. In many cases, processes, procedures, and practices are intended to assist in resolution of siting considerations. Examples of practices identified through this work and used to support the resolution of siting considerations include configuring layouts at facilities under development to minimize interference with radar systems; engaging with local officials and municipalities to develop acceptable wind operation protocols for issues such as sound; and curtailing or turning off wind turbines at low wind speeds, particularly during the late summer and early autumn to protect bats from colliding with turbines.

Consistent with the observed anecdotal evidence, this work suggests that the net effect of multiple points of potential consideration for siting issues, executing processes and procedures to ensure responsible development, and enacting direct mitigating measures is often upward pressure on development costs and extended development timelines. In some cases, operating costs are also increased. Notwithstanding this upward pressure and the project-level risk associated with specific siting considerations, development costs remain a relatively small portion of all-in project capital costs.

In terms of project-level costs, interviews conducted within this effort suggested direct development costs are typically on the order of $\$ 40 /$ kilowatt $(\mathrm{kW})$ to $\$ 60 / \mathrm{kW}$, relative to the all-in average project cost for 2014 of $\$ 1,710 / \mathrm{kW}$. At the same time, certain portions of the development budget may increase as a function of specific issues emerging during the development process. For example, public engagement expenditures may increase by as much as 4 times, wildlife studies and research expenditures may increase by 4 times, and radar mitigation expenditures may increase by 23 times. In addition, potential indirect costs in the form of stalled and failed projects may result in total project 
development expenditures two to four times the cost of a single successful project, for each delivered and operating wind power project.

According to our interviews, some industry analysts expect the project development risk associated with siting to get more severe as more wind projects are installed. For this reason, a more in-depth look at state and federal regulations that wind project developers face today (e.g., wildlife restrictions, potential future regulation scenarios) would be useful when considering appropriate wind development, especially on public lands.

Based on the quantitative assessments considered here, the siting considerations of radar, public engagement, and wildlife species we selected do have an impact on the nationwide wind resource and subsequently on long-term capacity expansion modeling outcomes. In terms of resource availability, under the most restrictive siting conditions considered, $80 \%$ of the potential land-based wind resource capacity considered developable today could be affected by at least one of the siting considerations evaluated. This finding suggests that managing siting considerations is an essential part of the wind power business for much of the country. At the same time, the immensity of the U.S. wind resource still leaves more than $1,000 \mathrm{GW}$ of wind potential that may be unaffected by the siting considerations examined.

Long-term capacity expansion modeling results suggest that wind is an increasingly costeffective and competitive energy resource. By 2050, BAU scenarios support levels of wind deployment more than three times current levels with widespread geographic distribution of installed capacity. However, applying these siting restrictions in NREL ReEDS modeling results in reductions in 2030 and 2050 wind capacity of up to $14 \%$ and $28 \%$, respectively, under BAU conditions. Coupling siting considerations with limits on post-2020 transmission expansion has a modest incremental effect on results for BAU scenarios in 2030 (e.g., 0\%-5\%) but could result in a total reduction in 2050 economic wind deployment by up to $40 \%$, relative to the BAU-Standard scenario.

In this research, siting considerations did not preclude the realization of the Wind Vision Study Scenario in part due to the vast U.S. wind potential, which in the modeled framework allows for relatively efficient management of siting considerations. However, scenarios that reflected siting considerations and transmission restrictions did result in some shifts of deployed wind capacity, due to reliance on lower-quality sites and increased curtailment. In addition, the represented siting considerations and transmission restrictions affected cost metrics reported in Wind Vision. More specifically, cumulative electric-sector expenditures for the Study Scenario could increase by up to $4 \%$ on an NPV basis, under the most stringent siting scenarios considered (i.e., "combined high" wind-siting restrictions and no new post-2020 interregional transmission allowed).

Under these most extreme conditions, cost savings estimated relative to the Wind Vision Baseline Scenario are eliminated; however, less stringent siting restrictions still allow for cumulative savings to be associated with the Study Scenario. The cost variability observed here is comparable to the range of potential cost variability explored in Wind Vision as a function of potential differences in fossil fuel prices and wind technology advancements. These effects are expected to have minimal impact on the societal benefits 
also quantified in Wind Vision, and accordingly, the changes in savings and costs remain a fraction of the potential societal benefits associated with future wind power deployment.

It is unrealistic to expect that all U.S. wind resource areas will be evaluated and designated as available or unavailable for wind deployment in one comprehensive assessment. The time and cost expended by a developer to reach a determination for a given wind project may become a limiting factor. Thus, it could prove beneficial to develop mechanisms to identify the impacts of wind energy on affected wildlife and human uses, develop mitigation strategies, and encourage long-term land use and airspace planning to minimize potential disruption to appropriate wind deployment on private and government land.

On an individual project basis, the siting considerations examined here could add sufficient risk and additional cost, reducing project viability due to delays to cost adders and possibly leading to project cancellation. Additionally, many of these considerations have a strong dependency on state and local sensitivities that are not captured at a national level or within this modeling framework. Quantifying these potential impacts requires analysis at the project or developer portfolio level rather than at the national level as described in this study. Individual case studies showing the project development process in various regions would be helpful to validate the cost adders and land impacts. This requires additional in-depth conversations with developers and stakeholders.

Wind energy deployment in the United States is expected to continue in the next decades; however, the deployment scenarios analyzed here will be difficult to achieve without addressing siting considerations and other issues outlined in Wind Vision. Although the abundant cost-effective domestic wind resource provides numerous options for addressing siting considerations while minimizing electricity system costs, evaluation of these siting considerations at early stages in project development is vital for developers and stakeholders. Mechanisms to identify the impacts of wind energy on affected wildlife and human uses, develop mitigation strategies, and encourage long-term land use and airspace planning could also help minimize potential disruption of appropriate wind deployment on private and government land.

Future analytic work in this domain would benefit from more formal and larger survey efforts to better ascertain the relative representativeness of experiences captured in the semi-structured interviews considered here. In addition, higher-resolution data, in terms of geographic coverage and cost impacts, and more sophisticated siting consideration layers could enhance the representations of the siting considerations applied here and further inform the potential impacts of siting on wind deployment. 


\section{References}

LandScan dataset. 2009. Oak Ridge National Laboratory. Accessed December 7, 2012: http://www.ornl.gov/sci/landscan/.

Lopez, Anthony, Billy Roberts, Donna Heimiller, Nate Blair, and Gian Porro. 2012. U.S. Renewable Energy Technical Potentials: A GIS-Based Analysis. Golden, CO: National Renewable Energy Laboratory. NREL/TP-6A20-51946. http://www.nrel.gov/docs/fy12osti/51946.pdf.

NREL (National Renewable Energy Laboratory). 2012. Renewable Electricity Futures Study. Hand, M.M.; Baldwin, S.; DeMeo, E.; Reilly, J.M.; Mai, T.; Arent, D.; Porro, G.; Meshek, M.; Sandor, D. eds., 4 vols. Golden, CO: National Renewable Energy Laboratory. NREL/TP-6A20-52409. http://www.nrel.gov/analysis/re futures/.

Short, Walter, Patrick Sullivan, Trieu Mai, Matthew Mowers, Caroline Uriarte, Nate Blair, Donna Heimiller, and Andrew Martinez. 2011. Regional Energy Deployment System (ReEDS). Golden, CO: National Renewable Energy Laboratory. NREL/TP-6A246534. http://www.nrel.gov/docs/fy12osti/46534.pdf.

DOE (U.S. Department of Energy). 2008. 20\% Wind Energy by 2030: Increasing Wind Energy's Contribution to U.S. Electricity Supply. Washington, DC: DOE Office of Energy Efficiency and Renewable Energy. DOE/GO-102008-2567. www.nrel.gov/docs/fy08osti/41869.pdf.

DOE. 2015. Wind Vision: A New Era for Wind Power in the United States. Washington, DC: DOE Office of Energy Efficiency and Renewable Energy. DOE/GO-102015-4640. http://www.wind.energy.gov/windvision.

U.S. Fish and Wildlife Service. Eagle Conservation Plan Guidance. 2013. Accessed May 16, 2015: http://www.fws.gov/windenergy/eagle_guidance.html.

Wiser, Ryan, Mark Bolinger, Galen Barbose, Naïm Darghouth, Ben Hoen, Andrew Mills, Kristina Hamachi LaCommare, Dev Millstein, Dana Hansen, Kevin Porter, Rebecca Widiss, Michael Buckley, Frank Oteri, Aaron Smith, and Suzanne Tegen. 2015. 2014 Wind Technologies Market Report. Washington, DC: DOE Office of Energy Efficiency and Renewable Energy. DOE/GO-102015-4702. http://energy.gov/sites/prod/ files/2015/08/f25/2014-Wind-Technologies-Market-Report-8.7.pdf.

Zayas, Jose, Michael Derby, Patrick Gilman, Shreyas Ananthan, Eric Lantz, Jason Cotrell, Fredric Beck, and Richard Tusing. 2015. Enabling Wind Power Nationwide. Washington, DC: U.S. Department of Energy. DOE/EE-1218. http://energy.gov/sites/ $\mathrm{prod} /$ files/2015/05/f22/Enabling Wind Power Nationwide_18MAY2015_FINAL.pdf. 


\section{Appendix A. Detailed Project Development Flowcharts}

The following flowcharts and discussions describe the essential components of the wind energy project development process. Figure A-1 presents an overview of the entire development process, including construction and operations. ${ }^{23}$ The five subsequent sections provide a detailed description of each of these stages, highlighting the important prospecting variables as well as the parameters that are addressed throughout the development process.

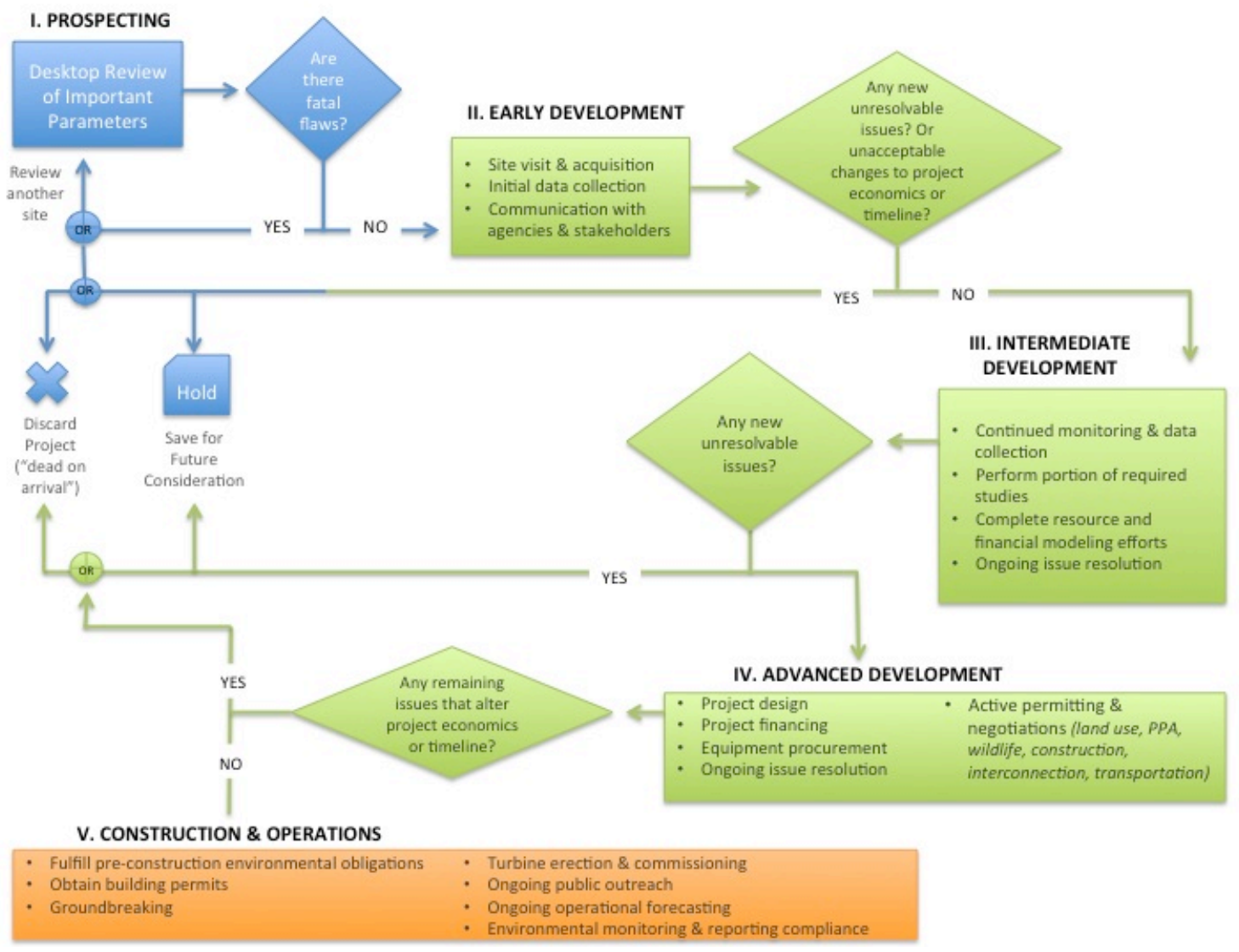

Figure A-1. Overview of development process

\section{Stage I: Prospecting}

The first stage of the wind project development process is prospecting (Figure A-2). During prospecting, the developer identifies and assesses potential sites for general feasibility. Prospecting is typically informed by a desktop-level review of a wide array of parameters that might affect a particular project. At this stage, the developer relies on in-

\footnotetext{
${ }^{23}$ Within the flowcharts, rectangles represent processes, diamonds represent decisions, parallelograms represent data, and rectangles with a wavy base represent documents.
} 
house expertise, publicly available data, and, in some cases, external consultants. Data gathering and analysis build an understanding of the potential for a specific wind power project and identify how a given project compares with other potential projects in the same market. The developer assesses the available transmission capacity, evaluates the presence of sensitive species and habitat, and identifies potential issues with radar, local land use and zoning laws, permitting requirements, attitudes toward wind energy, and the political environment. In some cases, a site visit or purchase of wind resource data may be necessary. Land acquisition and an initial meteorological tower installation may also occur. The steps in prospecting are to assess market strength, evaluate project economics, and determine permitting needs.

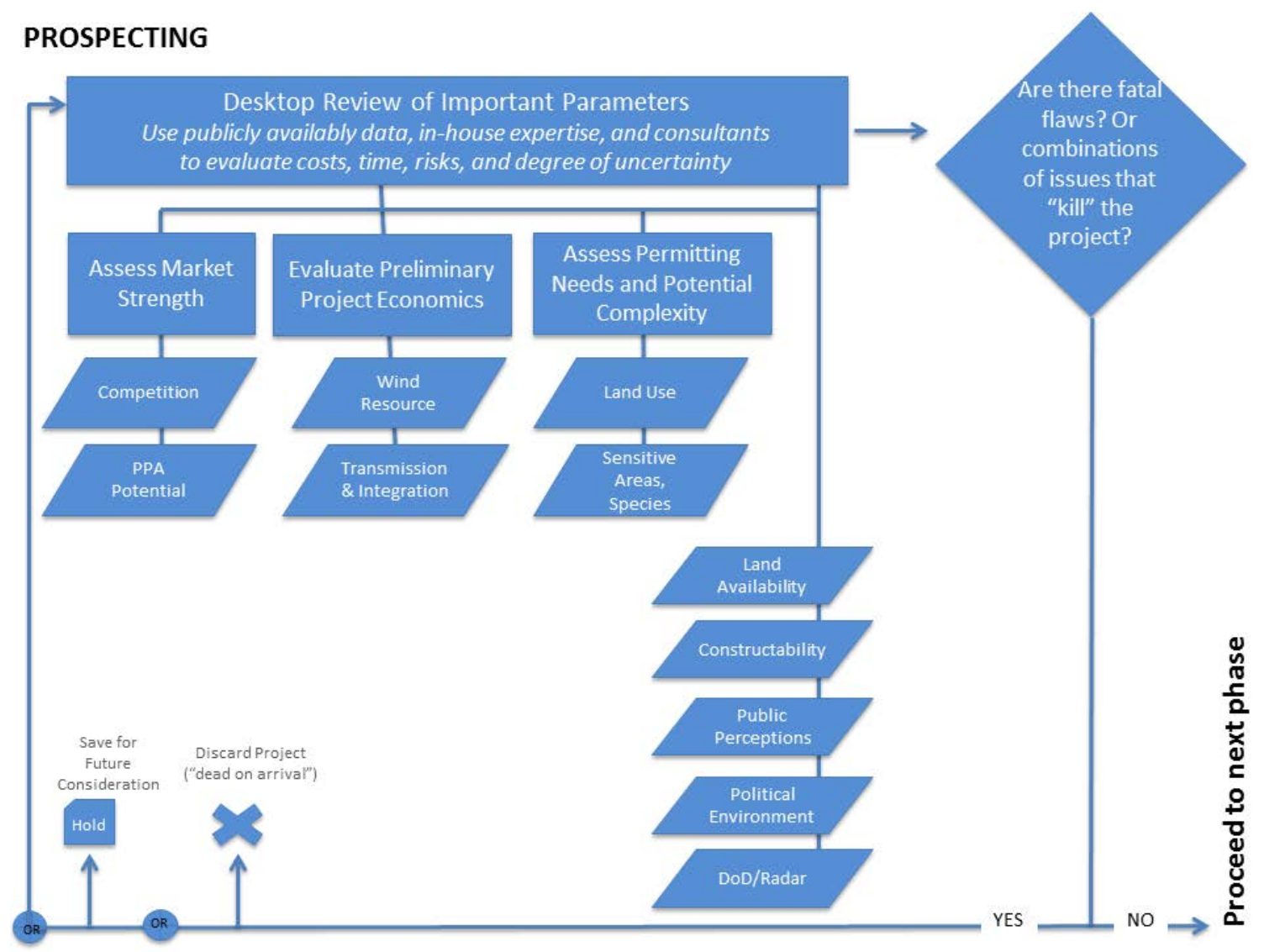

Figure A-2. Stage I of the development process: prospecting

Two questions underlie all prospecting work. First, are there any fatal flaws—existing conditions that prohibit the developer from moving forward or that would immediately impose prohibitively high costs? Potential fatal flaws include too much competition, an inadequate resource (e.g., net capacity factor too low), or permitting complexity (Figure A-3). Second, are there uncertainties that could preclude delivering a project within a reasonable timeframe or budget? Uncertainties that a developer might identify during the prospecting stage include changes in state or federal regulations specific to a given species in the area, changes in state or local political leadership, or revelations that publicly available resource data are limited, outdated, or otherwise flawed (Figure A-4). 


\section{PROSPECTING: Potential Issues or Fatal Flaws}

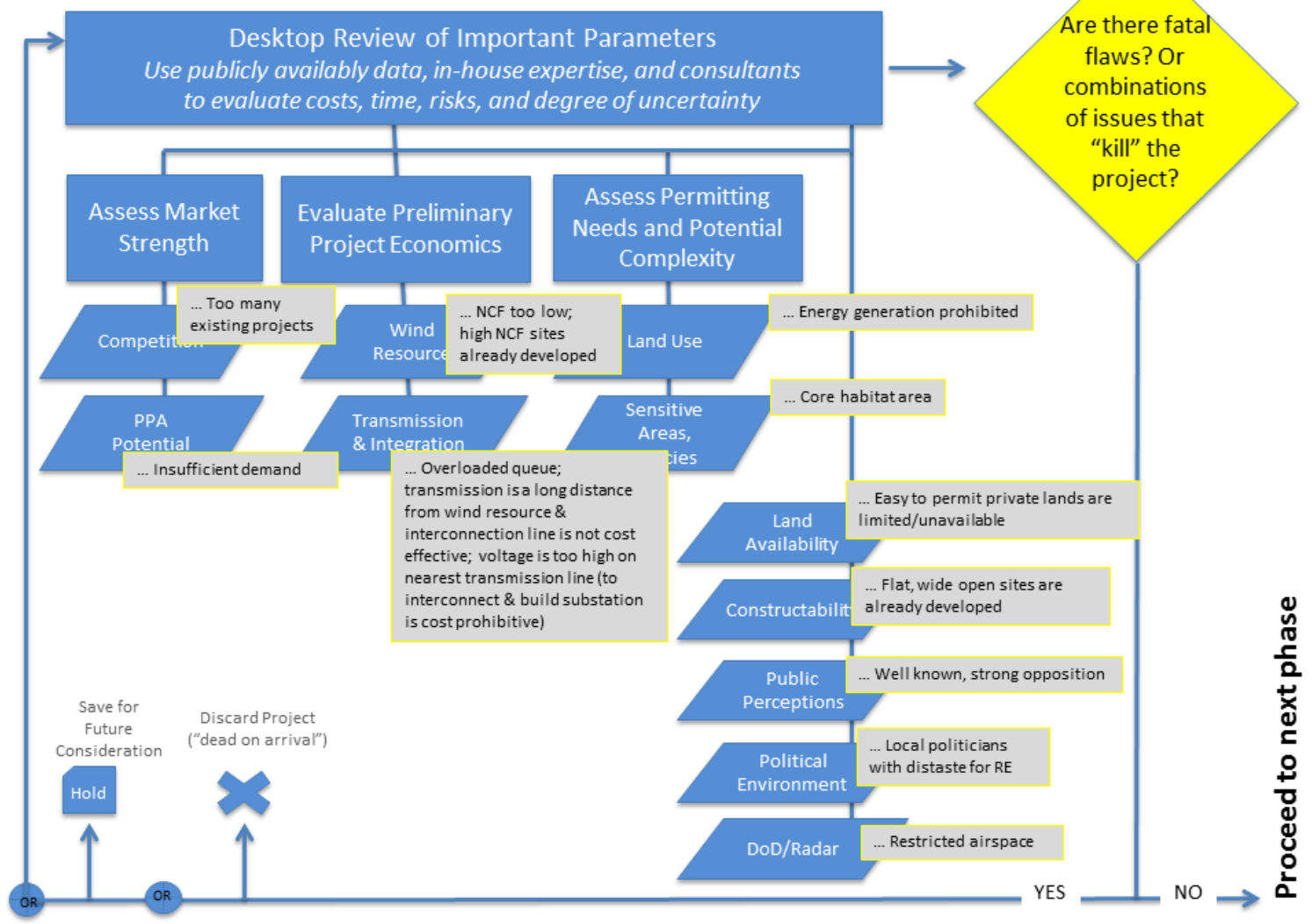

Figure A-3. Potential fatal flaws during the prospecting stage 


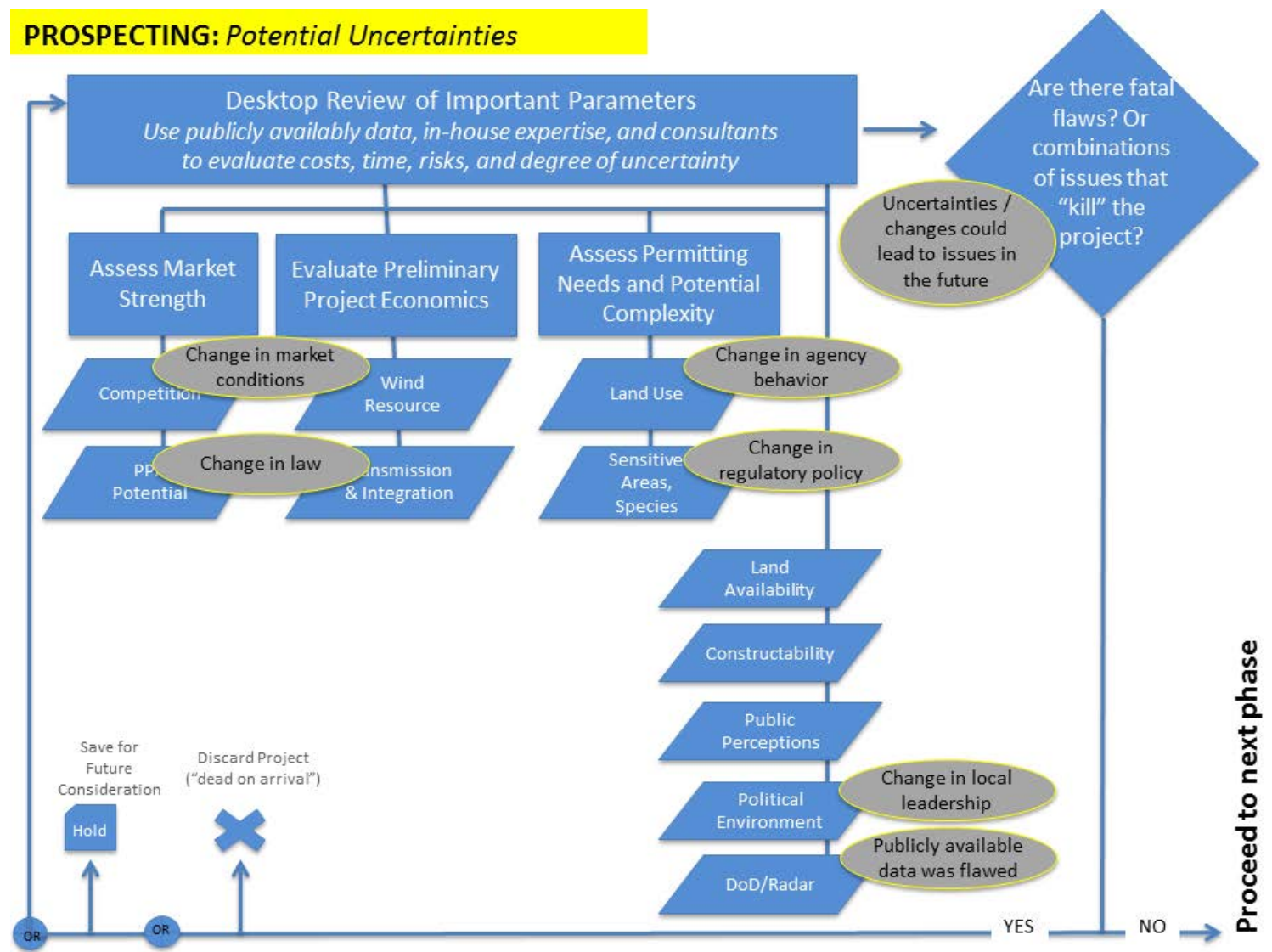

Figure A-4. Potential uncertainties during the prospecting stage 


\section{Stage II: Early Development}

A project that successfully passes through prospecting reaches early development (Figure A-5). Early development involves a more comprehensive and resource-intensive (time and financial) evaluation of project economics and feasibility. In addition, the developer conducts site visits; initiates or continues efforts to acquire land; deploys mechanisms for data collection, including meteorological towers; begins a more thorough wildlife assessment; and initiates informal contact with regulatory agencies. The developer also adds the project to the transmission interconnection process (unless this was done during prospecting) and initiates a grid system impacts study. In addition, the developer may create a public relations or outreach plan and begin developing supporting materials for their project. Selected activities at this stage are typically formalized as a critical issues analysis. The critical issues analysis entails a more thorough and documented assessment of potential fatal flaws or red flags. The critical issues analysis may be conducted using either in-house expertise or a consultant.

\section{EARLY DEVELOPMENT}

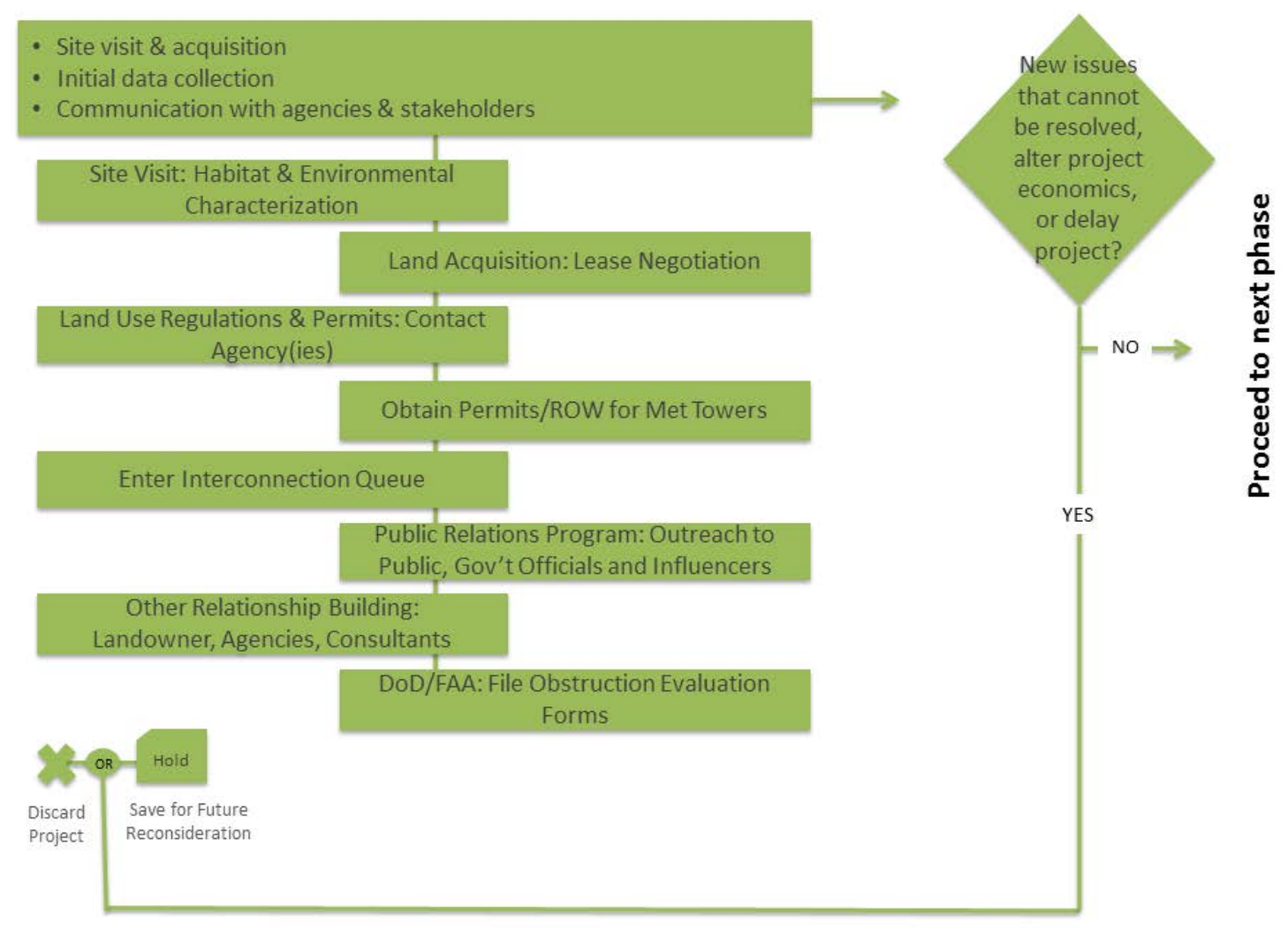

Figure A-5. Stage II of the development process: early development

During early development, the developer continues to pose the same two underlying questions. First, "are there any fatal flaws?" Second, "are there uncertainties that could preclude delivering a project within a reasonable timeframe or budget?" However, the triggers that developers look for in terms of fatal flaws and red flags evolve as the project matures (Figure A-6). During early development, problematic issues may include discovery of a subset of landowners unwilling to sell or lease their land and the 
realization that the planned point of interconnection does not yet exist or that changes to local ordinances will be required.

\section{EARLY DEVELOPMENT: Potential Issues}

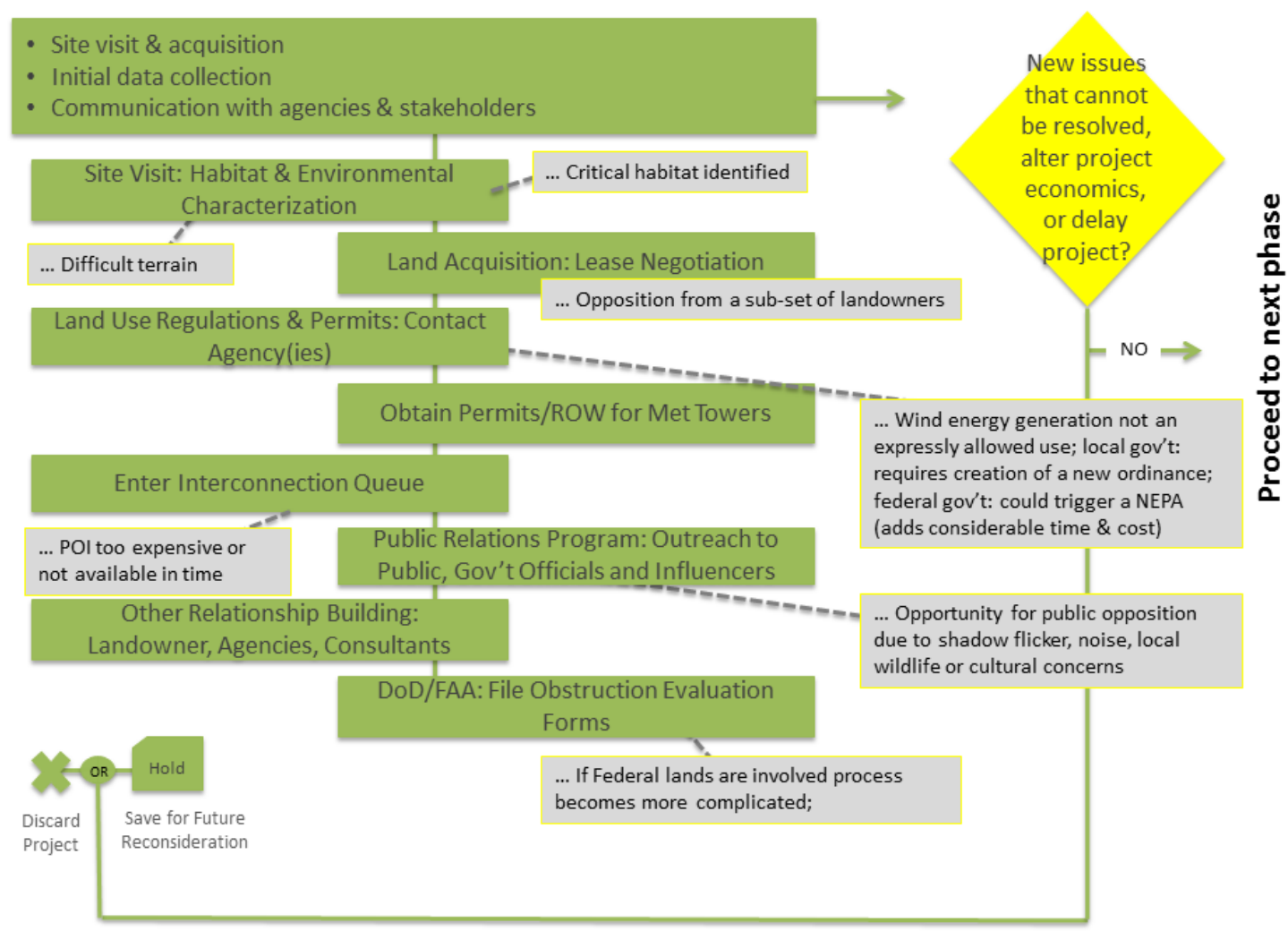

Figure A-6. Potential fatal flaws during early development 


\section{Stage III: Intermediate Development}

In the intermediate development stage (Figure A-7), the developer commences significant on-site activity. Additional meteorological towers or remote-sensing tools may be installed, and major long-term biological and wildlife data collection begins. In addition, the interconnection process is advanced to the next phase with a feasibility study, a system impact study, or both. Land acquisition and public relations strategies are finalized and the developer moves these plans forward. During intermediate development, a majority of the required land is under the developer's control. Formal engagement of regulatory and permitting agencies related to land use, environmental and wildlife issues, and radar occurs, and the initial permitting paperwork is submitted. The developer also moves forward with off-take planning by submitting a response to a formal request for proposals or by initiating negotiations regarding a PPA.

\section{INTERMEDIATE DEVELOPMENT}

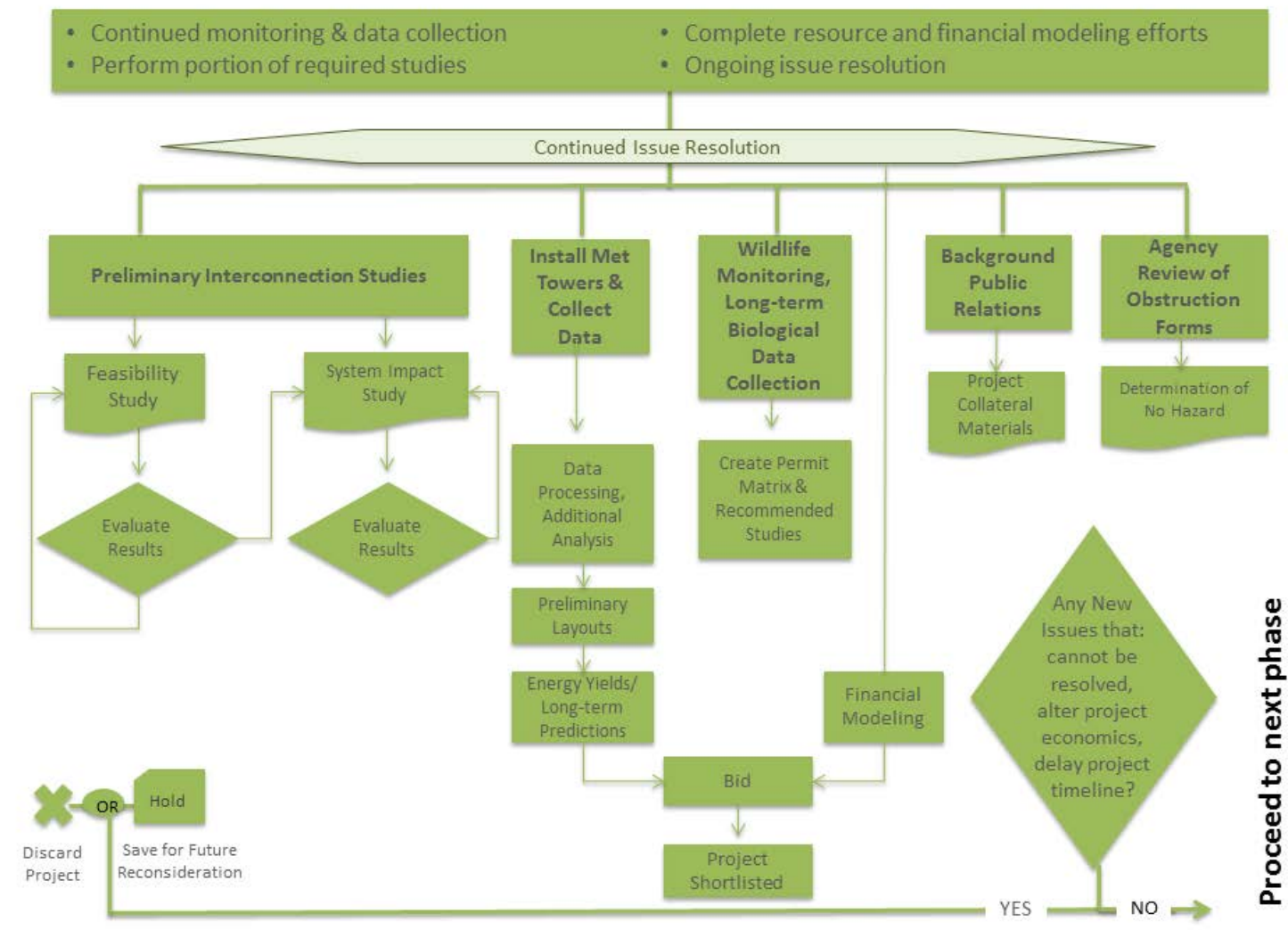

Figure A-7. Stage III of the development process: intermediate development 
As intermediate development proceeds and new information is obtained, the developer continues to seek out fatal flaws or uncertainties that could result in a delayed or overbudget project. Figure A-8 highlights potential fatal flaws that might be encountered during intermediate development, including cost-prohibitive wheeling charges, insufficient capacity on transmission lines, or difficulty securing a PPA.

\section{INTERMEDIATE DEVELOPMENT: Potential Issues}

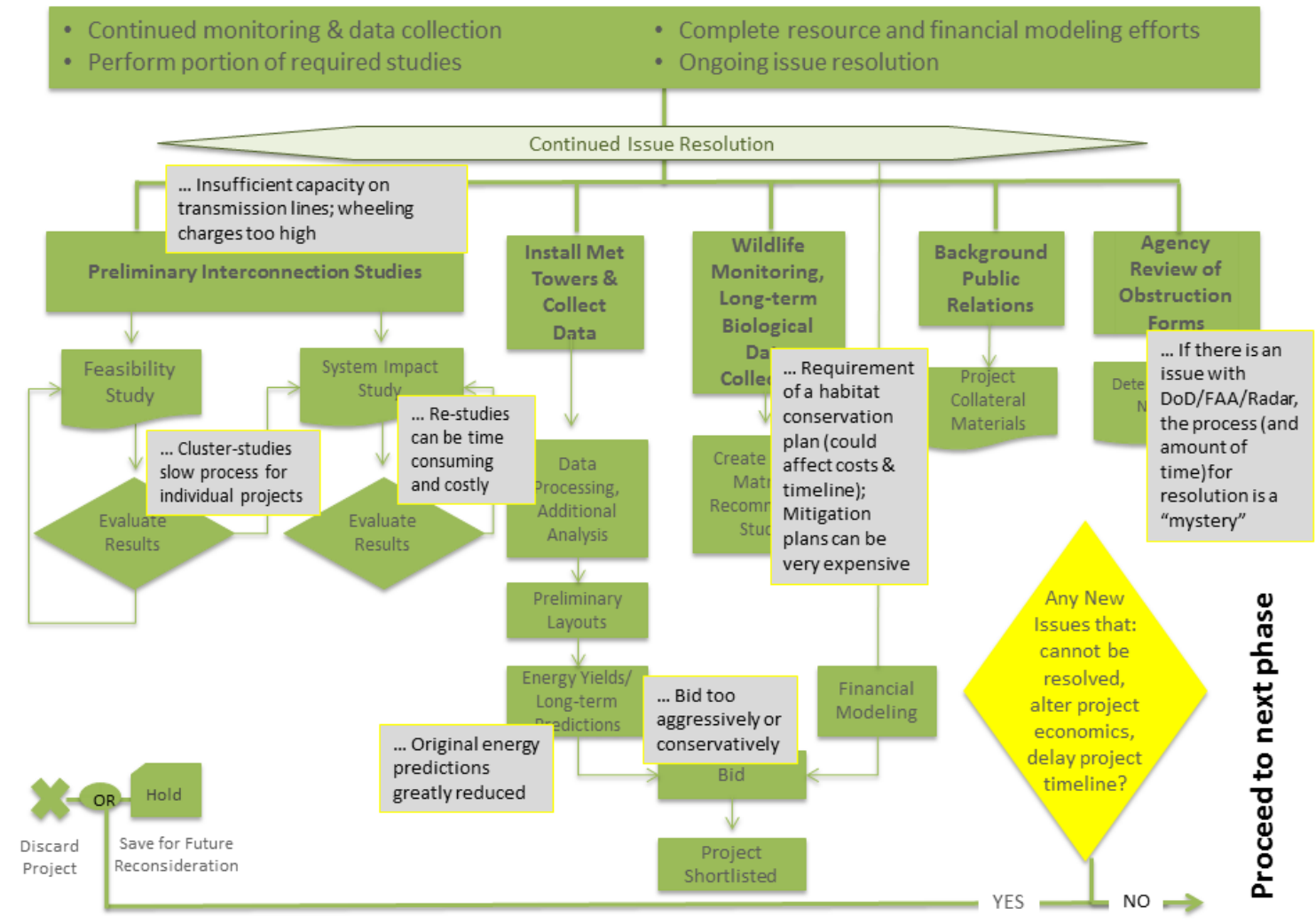

Figure A-8. Potential fatal flaws during intermediate development 


\section{Stage IV: Advanced Development}

The fourth stage of development activity is advanced development (Figure A-9). While some developers do not move formally into advanced development until all major permits have been obtained, this stage generally involves finalizing permits, initiating project financing, and negotiating PPAs. It also entails completing any remaining wildlife studies, developing the final wind resource report, securing a wind turbine supply contract, and finalizing the interconnection process (i.e., the facilities study and the transmission services request). During this stage, the developer also completes land acquisition and project design and initiates equipment procurement for items with long lead times such as transformers and pad mounts.

\section{ADVANCED DEVELOPMENT}

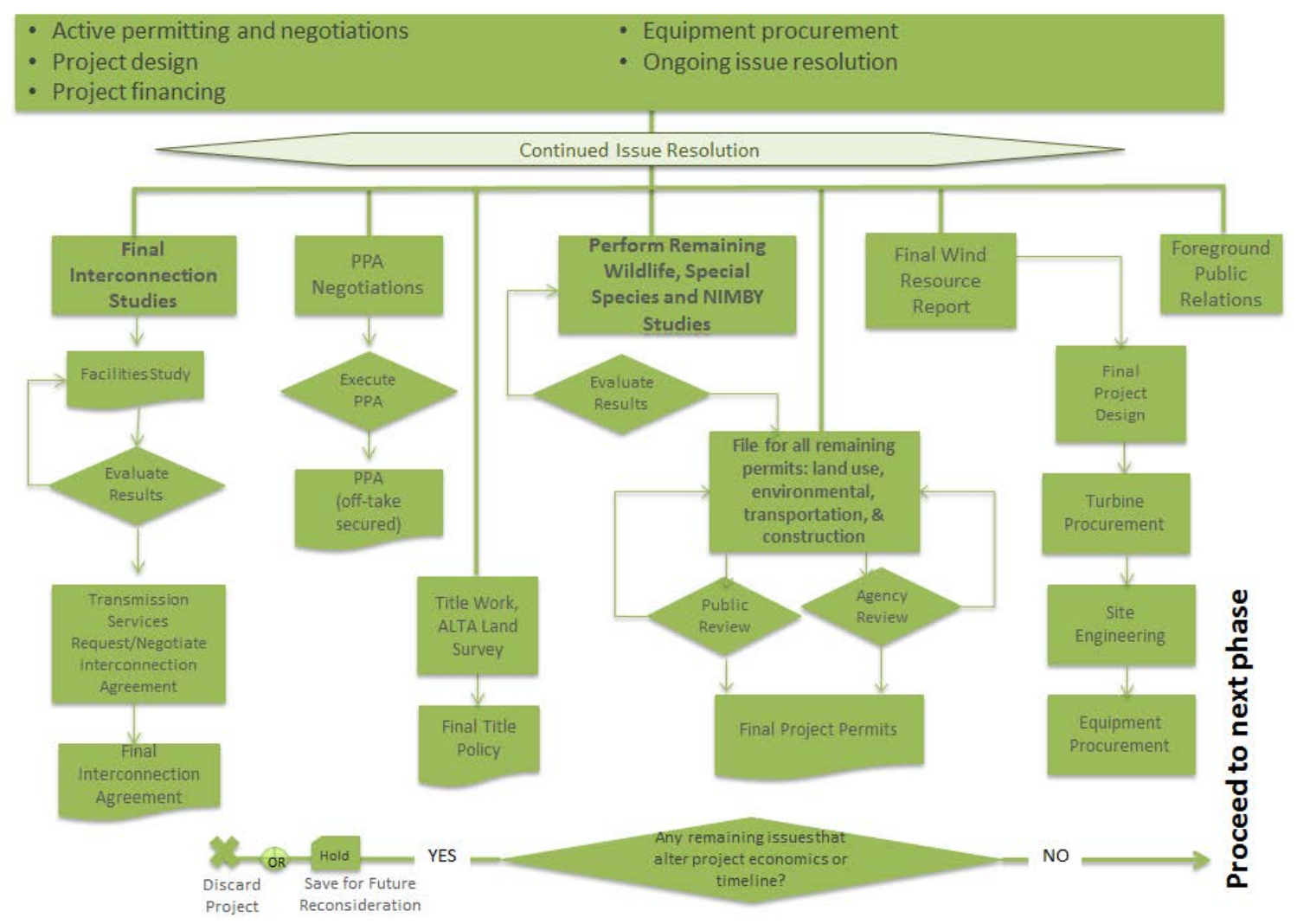

Figure A-9. Stage IV of the development process: advanced development

Even during the advanced development stage the developer continues to pursue any remaining fatal flaws or red flags. Possible fatal flaws that might be identified during advanced development (Figure A-10) include supply constraints for critical equipment, breakdowns in negotiations with the utility, or changes in regulatory policy (e.g., wildlife-related policy) that might prevent the project from moving forward. 


\section{ADVANCED DEVELOPMENT: Potential Issues}

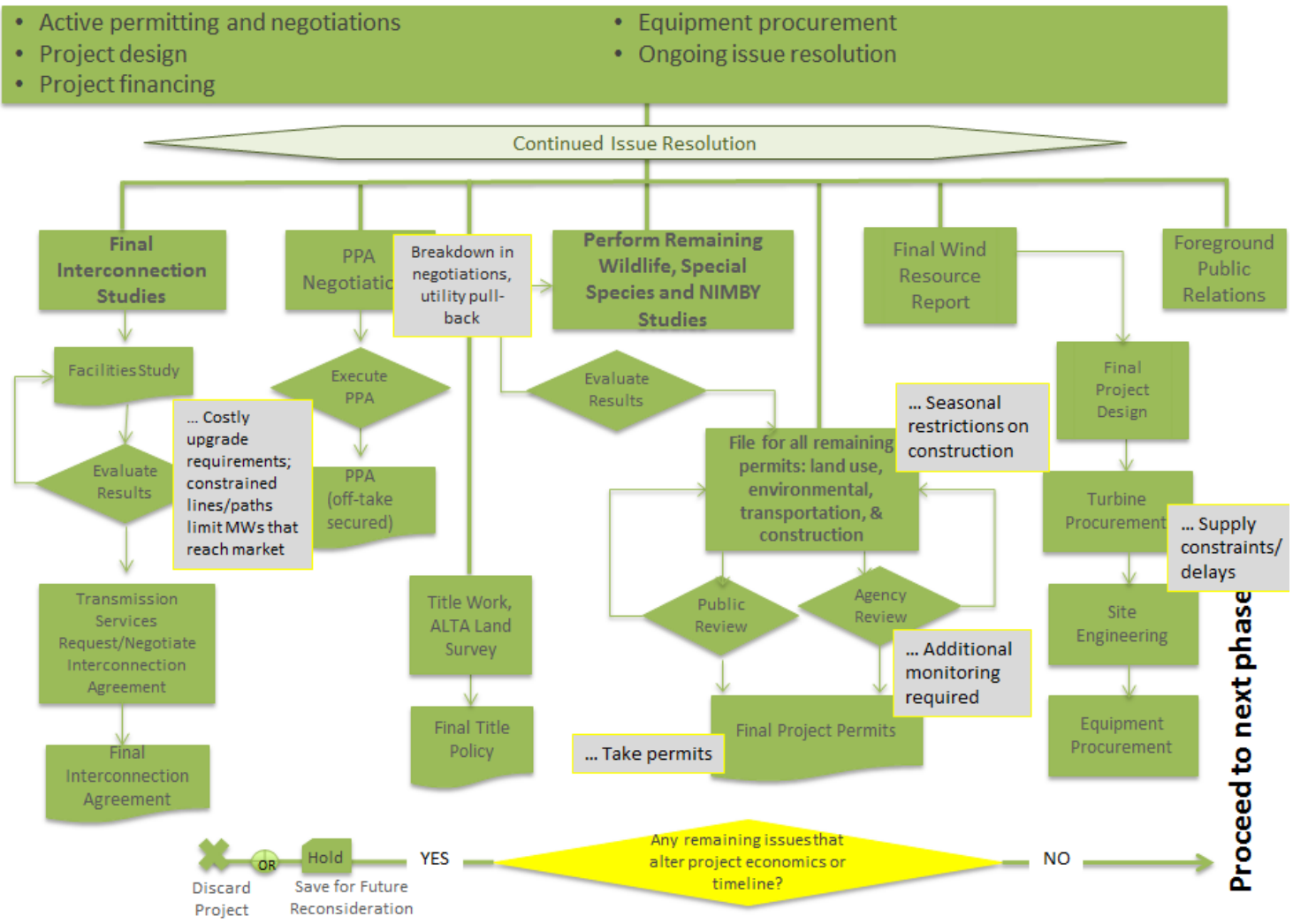

Figure A-10. Potential fatal flaws during advanced development 


\section{Appendix B. Siting Consideration Impact Maps}

Figure B-1 shows the U.S. wind energy resource at 80 meters. This resource potential was also used in DOE's Wind Vision, but this analysis does not include the potential for increased opportunity noted in the recent DOE report Enabling Wind Power Nationwide (Zayas et al. 2015). Figures B-2 through B-5 show public engagement, radar, and combined wildlife scenarios in GIS format. In these areas, proponents of new wind power projects will need to negotiate acceptable solutions with stakeholders to share land and airspace with the other uses.

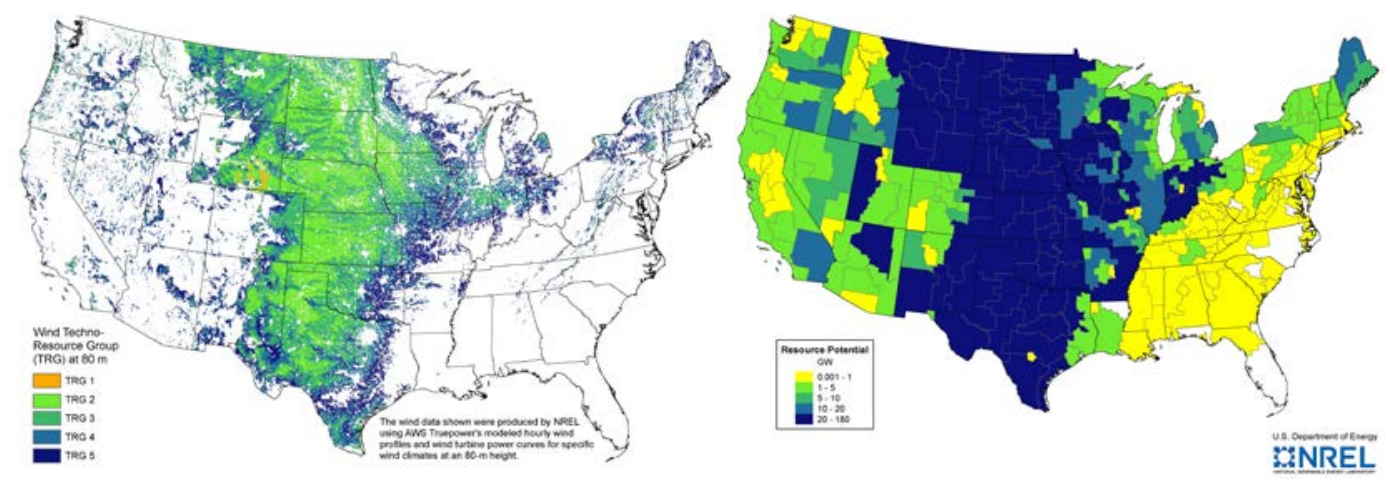

Figure B-1. Map of the United States wind resource quality (left) and quantity (right) with standard restrictions applied

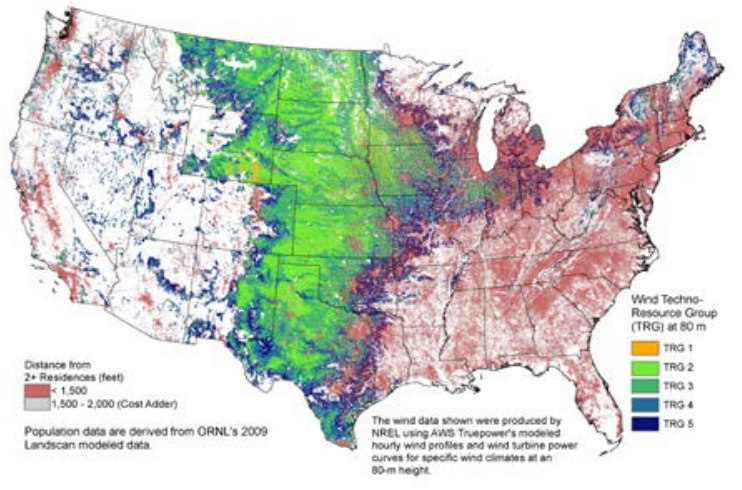

Figure B-2. U.S. wind resource quality with the moderate public engagement representation

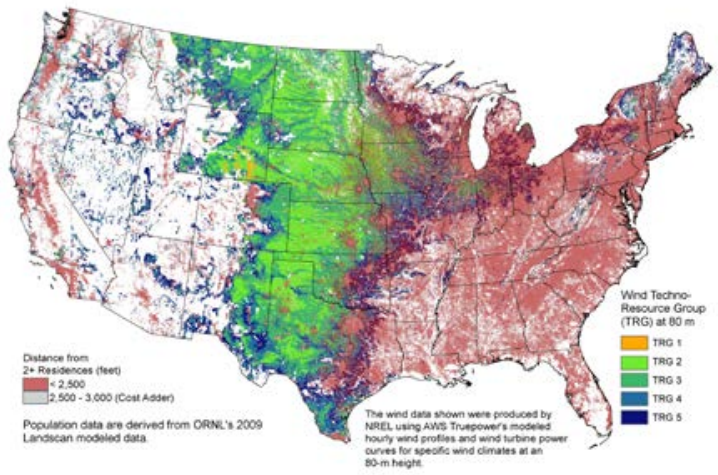

Figure B-3. U.S. wind resource quality with the higher public engagement representation 


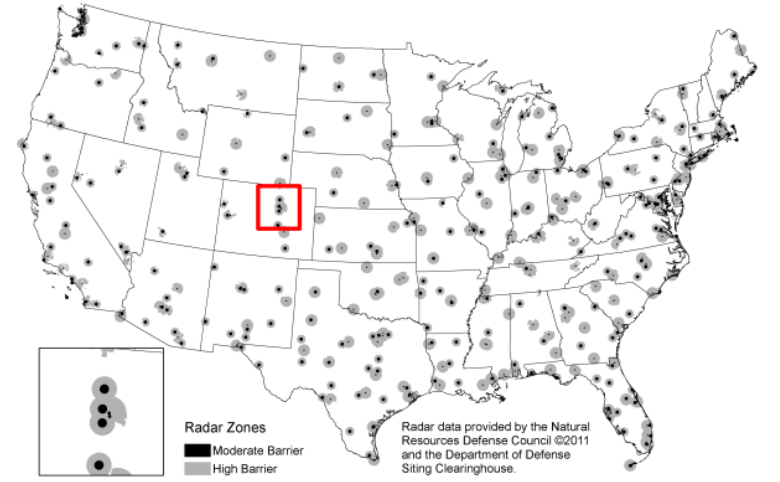

Figure B-4. Moderate and highly restrictive radar representations

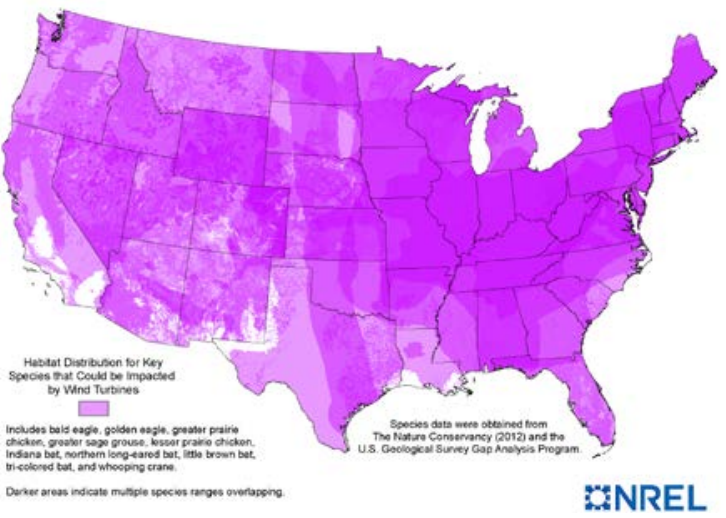

Figure B-5. Avian and bat species identified for wind wildlife interaction and considered in this work 


\section{Appendix C. Wind Resource and Federal Land}

As shown in Figure C-1, areas with strong wind capacity overlap with federal lands. Much of the potential capacity on federal lands is considered off limits for development due to national monument or park designations, steep slopes, or other physical or cultural characteristics. In NREL's Standard Exclusion scenario, $43.8 \%$ of all federal lands are excluded from development. Table $\mathrm{C}-1$ details the impacts of federal lands on the remaining resource potential by TRG.

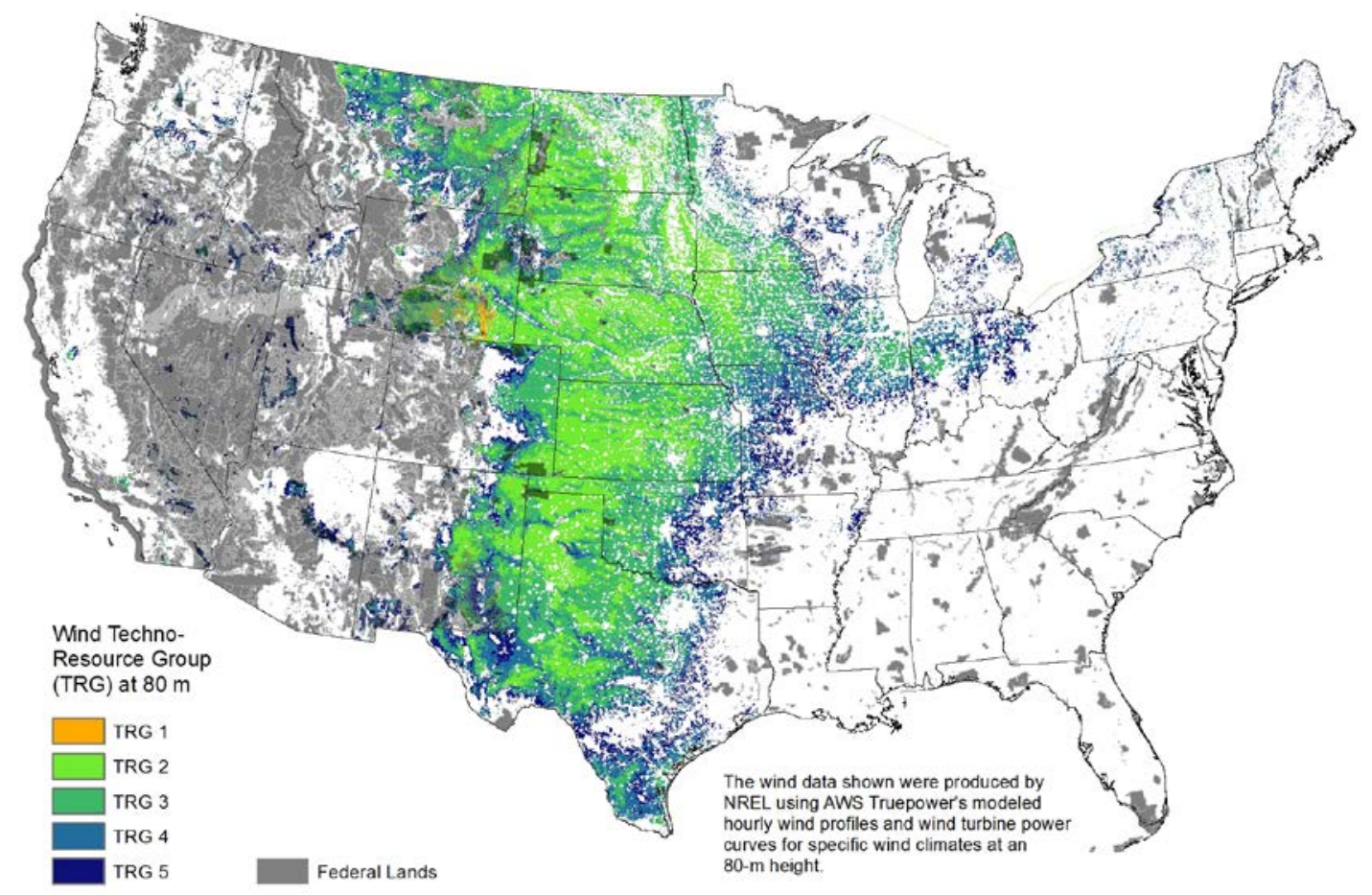

Figure C-1. U.S. wind resource at $80 \mathrm{~m}$ overlaid with federal lands

Table C-1. Impact of Federal Lands on Developable Area (Capacity) of Wind Vision by TRG

\begin{tabular}{|c|c|c|c|c|c|c|}
\hline TRG & $\begin{array}{r}\text { TRG1 } \\
\text { (GW) }\end{array}$ & $\begin{array}{l}\text { TRG2 } \\
\text { (GW) }\end{array}$ & $\begin{array}{l}\text { TRG3 } \\
\text { (GW) }\end{array}$ & $\begin{array}{l}\text { TRG4 } \\
(\mathbf{G W})\end{array}$ & $\begin{array}{l}\text { TRG5 } \\
\text { (GW) }\end{array}$ & $\begin{array}{l}\text { Quantity of } \\
\text { Standard } \\
\text { Resource } \\
\text { Affected }\end{array}$ \\
\hline Standard & 70 & 1,171 & 2,429 & 1,175 & 1,323 & -- \\
\hline $\begin{array}{l}\text { Federal } \\
\text { Restriction }\end{array}$ & 64 & 1,134 & 2,283 & 1,065 & 1,111 & $8 \%$ \\
\hline
\end{tabular}

